\title{
¿Privarlas de libertad es privarlas de salud? Interlocuciones entre género, salud pública y prisión a partir de la experiencia de un equipo de atención básica
}

\author{
Bárbara Sordi Stock \\ Instituto Andaluz Interuniversitario de Criminología - IAIC/US/España \\ barbarasordistock@gmail.com
}

\section{Renata Maria Dotta Panichi}

Secretaría de Salud del Estado. Departamento de Políticas en Prisión - SES/RS/Brasil renata-panichi@saude.rs.gov.br

\section{Aline Mattos Fuzinatto}

Secretaría de Salud del Estado. Departamento de Políticas en Prisión - SES/RS/Brasil alinefuzinatto@gmail.com

\section{Resumen}

En el presente artículo, se expondrán los resultados de una pesquisa acción para conocer la situación psicosocial de las reclusas, así como el trabajo ejecutado por el equipo de atención básica de salud (EABp) en una prisión de Brasil. La investigación se ha valido de la pluralidad metodológica, en particular, de dos grupos focales combinados con seis meses de soporte matricial a dicho equipo. Entre los resultados, se destaca que las carencias de la atención a la salud intramuros están relacionadas tanto con la fragmentación de los cuidados y las redes de salud existentes en el ámbito comunitario, como con los conocimientos insuficientes sobre las especificidades de género en prisión. La línea de cuidado sobre salud en prisión desde una perspectiva de género, corolario del proyecto, refuerza la necesidad de diseñar políticas públicas fundamentadas en la evidencia científica.

Palabras clave: grupo focal; ruta de victimización; salud intramuros; soporte matricial 
Abstract. Is Denying Women Freedom the Same as Denying Them Health?: Conversations about Gender, Public Health and Prison Based on the Experience of a Health Care Team

This article discusses the results of action research on the psychosocial situation of female inmates and the work of a basic health care team (EABp) in a Brazilian women's prison. The research was carried out by means of methodological pluralism. In particular, two focus groups combined with six months of matrix support for the team were used. The results highlight that the shortcomings of intramural health care are related to both the fragmentation of health care and the existing health networks at the community level, as well as insufficient knowledge of gender specificities in prison. Research on health care in prison from a gender perspective, a corollary of the project, reinforces the need to design public policies based on scientific evidence.

Keywords: focus group; road to victimization; health in prison; support matrix

\begin{aligned} & \multicolumn{2}{c}{ Sumario } \\ & Introducción 5. Resultados \\ & 1. Antecedentes y estado de la cuestión 6. Discusión y conclusión \\ & 2. Objetivos Referencias bibliográficas \\ & 3. Hipótesis de partida Normativa \\ & 4. Método \end{aligned}

\section{Introducción}

El artículo recoge los resultados de la investigación titulada La situación de las mujeres privadas de libertad y el soporte matricial en salud mental a los Equipos de Atención Básica (EABP) insertos en el sistema carcelario y desarrollada en una cárcel de mujeres del sur de Brasil. Se trata de una pesquisa acción pionera, interinstitucional e interdisciplinar para conocer la situación psicosocial de las reclusas, así como el trabajo ejecutado por el equipo de atención básica de salud en funcionamiento en la prisión (en adelante, EABp).

La puesta en marcha de este proyecto se enmarca en un proceso amplio y reciente de pensar y producir salud intramuros en el que hay que considerar distintos factores. De entre ellos, se quiere destacar:

1. El vertiginoso incremento de la población de mujeres en contacto con la justicia penal y las especificidades que presenta la ejecución de la pena desde una perspectiva de género.

2. La ausencia de datos y de indicadores sobre la atención y la promoción de su salud en prisión.

3. La puesta en marcha de dos políticas de alcance nacional: la Política Nacional de Atenção às Mulheres em Situação de Privação de Liberdade e Egressas do Sistema Prisional (PNAMP, 2014) y la Política Nacional de Atenção Integral à Saúde à Pessoa Privada de Liberdade no Sistema 
Prisional (PNAISP, 2014), esta última inspirada en la experiencia de la Secretaría de Salud del Estado de Rio Grande del Sur, órgano responsable de la investigación.

Este novedoso escenario sugiere la necesidad de producir conocimiento científico que contribuya a que la atención, el cuidado y la promoción de la salud de las reclusas pasen de dispositivos formales a una práctica asumida por las instituciones responsables de su custodia, así como también por todos aquellos órganos responsables de garantizar su derecho fundamental a la salud.

\section{Antecedentes y estado de la cuestión}

\subsection{El derecho y el cuidado a la salud en prisión}

La carta constitucional democrática brasileña de 1988 (en adelante, CF) previó expresamente que la salud es un derecho de todos los ciudadanos y un deber del Estado (art. $196 \mathrm{CF}$ ). Para lograr lo dispuesto en ley, se ha puesto en marcha el Sistema Único de Saúde, popularmente conocido como SUS, cuyas directrices son la universalidad, la igualdad de acceso y la equidad de asistencia en la salud (Ley 8.080/1990 y Ley 8.142/1990).

En prisiones, sin embargo, los avances han sido ínfimos. Ni tan siquiera las disposiciones de la Lei de Execuções Penais (en adelante, LEP; Ley 7.210/1984), que regulan el derecho a la atención médica, farmacológica y odontológica intramuros, eran objeto del desarrollo práctico debido. Este diagnóstico se agrava al observar que la LEP es anterior a la carta constitucional y a la reforma sanitaria, es decir, propone una visión de salud meramente curativa y desenfocada de la idea amplia de cuidado establecida en el SUS.

A fin de garantizar el acceso a la salud dentro de los establecimientos penitenciarios, los ministerios de Justicia y Salud de Brasil publicaron el Plano Nacional de Saúde no Sistema Penitenciario (PNSSP. Portaria Interministerial n. $\left.{ }^{o} 1.777 / 2003\right)$. Este Plan consistió en la puesta en marcha de un trabajo integrado y multidisciplinar por medio de un EABp, compuesto por siete profesionales de salud en prisiones con más de 100 reclusos y reclusas. Concretamente, en dicho equipo, participan un psicólogo, un asistente social, un médico, un enfermero, un técnico de enfermería, un odontólogo y un auxiliar de odontólogo.

El PNSSP ha representado un avance, pues ha planteado un trabajo bajo la perspectiva de atención integral que ha de ser ejecutada por profesionales de distintas áreas de conocimiento. No obstante, pasadas las primeras señales de euforia tras su publicación, los cambios en el día a día de las prisiones se revelaron parcos. Entre otras razones, a causa del escaso financiamiento del gobierno para la implementación de los EABp.

Concentrar esfuerzos en la salud de los presos era una necesidad irrenunciable. Las paupérrimas condiciones estructurales de los centros (antiguos, 
insalubres, sin material de higiene, etc.), junto a la sobrepoblación, habían hecho de los reclusos y de las reclusas sujetos extremamente vulnerables al desarrollo de enfermedades. Los casos de VIH/SIDA, hepatitis B y C, tuberculosis, sífilis y los problemas de salud mental eran, y continúan siendo en menor medida, frecuentes entre ellos y ellas (Canazaro y Argimon, 2010; Ferreira-Júnior et al, 2013; UNAIDS-OMS, 2007).

Hablando sobre la interseccionalidad entre salud y mujeres, el diagnóstico adquiría rasgos aún más preocupantes ante la ausencia de datos sobre las especificidades de género en prisiones. En la esfera internacional, esta temática ya venía formando parte de una serie de publicaciones científicas que, en mayor o menor medida, favorecieron el diseño de políticas públicas (Almeda-Samaranch y Bodelón, 2007; Proyecto MIP, 2005; Yagüe-Olmos, 2002; Del Val-Cid y Viedma-Rojas, 2012). Es más, con la publicación de las Reglas de Bangkok (2011) por parte de las Naciones Unidas, la atención a las especificidades de género en prisión recibirían atención privilegiada, con lo que Brasil debió acomodarse a esta nueva normativa.

Llegados a este punto, quiere resaltarse que, en Brasil, tras más de dos décadas de previsión de la salud como un derecho fundamental y de casi diez años de vigencia de una política pública sanitaria específica intramuros, se ha hecho muy poco para asegurar el acceso a la salud de las mujeres en situación de confinamiento. Será la producción académica, a todas luces inspirada en las publicaciones internacionales, la que revele las necesidades de las reclusas y las especificidades de su encarcelamiento en nuestro país (Carvalho et al., 2006; Campos, 1999; Chies, 2008; Colares y Chies, 2010; Espinoza, 2004; Guedes, 2006; Lemgruber, 1999; Wolff et al., 2007; Wolff, 2010). Se ha denunciado, entre otras cuestiones, el alto índice de abusos de sustancias estupefacientes y de trastornos de estrés postraumático, realidad que representa un grave problema de salud pública (Dotta-Panichi, 2014; IV Seminário Nacional de Estudos Prisionais, 2014).

De cara a esta situación fáctica, el gobierno brasileño diseñó el Projeto Mulheres, con el notorio propósito de implementar un conjunto de acciones para conocer y atender las necesidades de la población de mujeres encarceladas. Como corolario, instituyó una comisión especial junto al Departamento Penitenciario Nacional (Depen) para la elaboración de propuestas y actividades en el marco del citado proyecto (Portaría 154/2012). Se destacan, por ejemplo, la realización del $1 .^{\circ}$ y del $2 .^{\circ}$ Encontro Projeto Mulheres (2012 y 2013, respectivamente), que culminaron con el diseño de un borrador de política nacional de atención a las mujeres en situación de privación de libertad. En lo que concierne a la salud, se ha proporcionado un lugar preferente en el 2. ${ }^{\circ}$ Encontro, momento en el cual se discutieron las nuevas estrategias que se estaban erigiendo en el Ministerio de Salud, no pocas inspiradas en las prácticas desarrolladas en el sur de Brasil.

Ahora bien, ha de esperarse hasta 2014 para que acontezca una verdadera revolución en las políticas públicas sobre salud en prisiones desde una perspectiva de género como resultado del efecto combinado de dos políticas gubernamentales: la Política Nacional de Atenção Integral à Saúde à Pessoa Privada de Liberdade no Sistema Prisional (PNÄISP - Portaria Interministe- 
rial n. ${ }^{\circ}$ 1/2014) y la Política Nacional de Atenção às Mulheres em Situação de Privação de Liberdade e Egressas do Sistema Prisional (PNAMP - Portaria Interministerial n. ${ }^{\circ}$ 210/2014).

Inspirada en la experiencia del Estado de Río Grande del Sur, la PNAISP (2014, 2014a) busca garantizar el acceso a la salud en el nivel de atención básica dentro de prisiones. Se apuesta por un trabajo integrado, multiprofesional y transdisciplinar de los EABp.

La PNAMP (2014) pretende reformular las prácticas del sistema carcelario, a fin de garantizar los derechos de las mujeres reclusas nacionales y extranjeras. Se establecen una serie de nuevas prácticas dirigidas a los responsables de la gestión de los centros penitenciarios, es decir, a los gobiernos locales. Además, establece la creación y/o la adaptación de un banco de datos con informaciones específicas sobre la mujer reclusa (trabajo, hijos, enfermedades, etc.), así como la incorporación de la perspectiva de género en la asistencia a la salud, psicosocial, religiosa, educacional, jurídica y laboral proporcionada por el centro penitenciario. Nótese que la PNAMP ha sido presentada en el 3. ${ }^{\circ}$ Encontro Projeto Mulheres (2014) y que la capacitación de los profesionales que trabajan en prisiones sobre las nuevas directrices ha sido uno de sus puntos clave.

Figura 1. Principales marcos normativos que han contribuido a garantizar y promover el derecho a la salud de las mujeres en prisión (1984-2014)

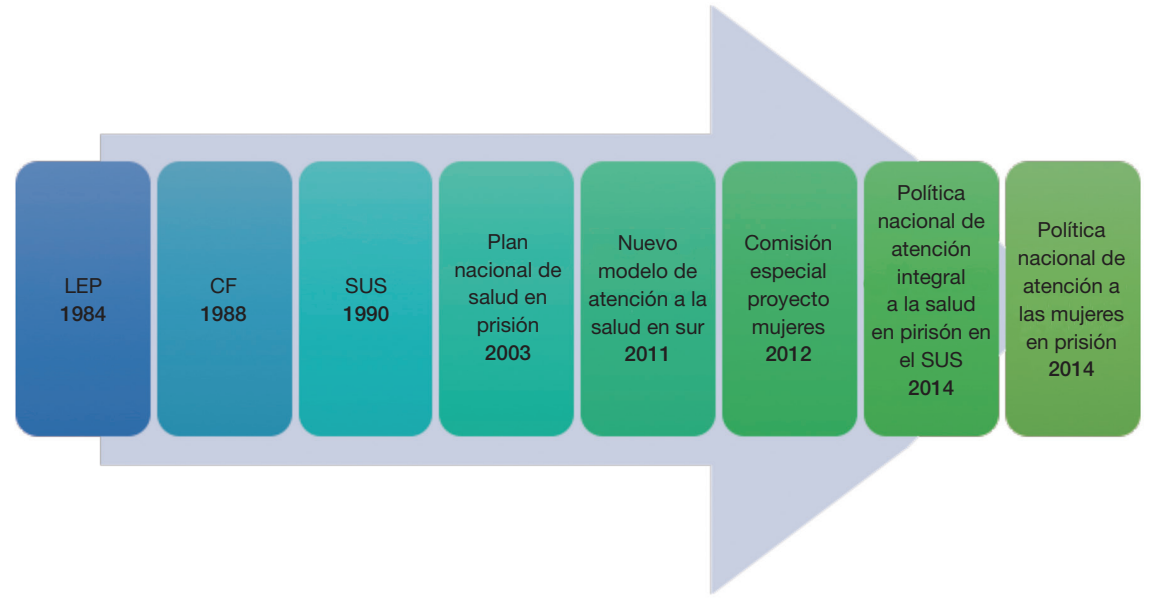

Fuente: elaboración propia.

\subsection{La postura pionera del Estado de Río Grande del Sur}

A partir de 2003, tras la puesta en marcha del PNSSP en el ámbito nacional y diferentemente a lo ocurrido en las demás regiones del país, el Estado de 
Río Grande del Sur reglamentó un conjunto de estrategias para garantizar la efectiva creación de una red de cuidados integrales a la salud de la persona privada de libertad (Resolución CIB - RS n.o 257/11). Se ha previsto, entre otras cuestiones, el cofinanciamiento de los equipos de salud y la cogestión del trabajo por medio de la municipalización del cuidado. Nuestro estado ha sido el primero en implantar una política pública sanitaria para la población privada de libertad, incentivada por el sistema de salud pública en vigor para la población fuera de prisiones, es decir, el SUS.

En 2009, la creación del Área Técnica con competencia específica en la atención integral a la salud de las personas privadas de libertad, vinculada al Departamento de Acciones en Salud de la Secretaría de Salud del Estado de Río Grande del Sur (DAS-RS), ha resultado determinante para cimentar las políticas públicas que se venían desarrollando en el ámbito regional ${ }^{1}$. Entre sus atribuciones, se encuentran el garantizar que la población privada de libertad tenga acceso a los recursos del SUS, la implantación de unidades básicas de salud dentro de las prisiones (en adelante, UBSp), el desarrollo de actividades de formación permanente y el diseño de una línea de cuidado de atención integral a la salud de las personas privadas de libertad ${ }^{2}$.

Trabajar a partir de una línea de cuidado es nada menos que apostar por la organización del itinerario que la persona requerirá para que su problema sanitario sea solucionado por una estructura adecuada, en el tiempo apropiado y respetando las especificidades del caso concreto ${ }^{3}$. La línea de cuidado funciona en base a proyectos terapéuticos: conjunto de actos pensados para resolver el problema de salud del individuo a partir de la evaluación del riesgo. Esta evaluación contempla, además de la dimensión clínica, aspectos sociales, económicos, ambientales y afectivos, es decir, un conjunto de aspectos que servirán de base para su diseño. Se trata de una verdadera mirada integral sobre la persona, y es competencia del equipo de salud responsable de la atención el accionar la red de recursos y servicios que el caso requiera (Franco y Magalhães, 2003; Pessôa, 2011).

En la organización de las competencias estatales, sean horizontales en el Estado de Río Grande del Sur, sean trasversales con los municipios y/o los

1. Con la aprobación de la PNAISP, en 2014, el Área Técnica de Atenção Integral às Pessoas Privadas de Liberdade no Sistema Prisional de la Secretaria de Salud de nuestro Estado también pasó a formar parte de dicha política nacional vinculada al Ministerio de Salud.

2. Acerca de dicha cuestión, podrá encontrarse información detallada en http://www.saude. rs.gov.br/

3. En otras palabras, línea de cuidado es una forma de organizar el trabajo respecto a la salud. Incorpora la idea de integralidad en la asistencia a la salud por medio de la unificación de acciones de prevención, curación y rehabilitación, al posibilitar que la persona disponga no solo de una estructura adecuada para encontrar una solución a su problema, sino también que este se resuelva en el tiempo adecuado y acorde a las especificidades del caso concreto. Entre las directrices básicas de una línea de cuidado, se destacan la acogida, el vínculo y la responsabilización. En otras palabras, se trabaja la calidad de la atención y de la escucha de los problemas de salud hasta la adecuada resolución y las posibles derivaciones (Franco y Magalhães, 2003; Franco y Franco, 2011; Pessôa, 2011). 
ministerios, la referida área técnica pasa a ser la responsable de ejecutar la gestión intersectorial y compartida entre la Secretaría de Salud, los servicios penitenciarios, los gestores del municipio, el Ministerio Público, la sociedad civil y el Ministerio de Salud. No obstante, el órgano responsable de planear y ejecutar la política penitenciaria en nuestra región es la Superintendência dos Serviços Penitenciários (en adelante, SUSEPE), vinculada a la Secretaria da Segurança Pública (en adelante, SSP). En otras palabras, esta última es quien vela por la ejecución de las penas privativas de libertad y las medidas de seguridad. Esta institución cuenta con la División de Salud, cuyas atribuciones son, entre otras, la compra de equipamientos para el área sanitaria y el acompañamiento de la implantación de las UBSp por parte de la Secretaría de Salud 4 .

\section{Gráfico 1. Evolución de los Equipos de Atención Básica en prisión (EABp)}

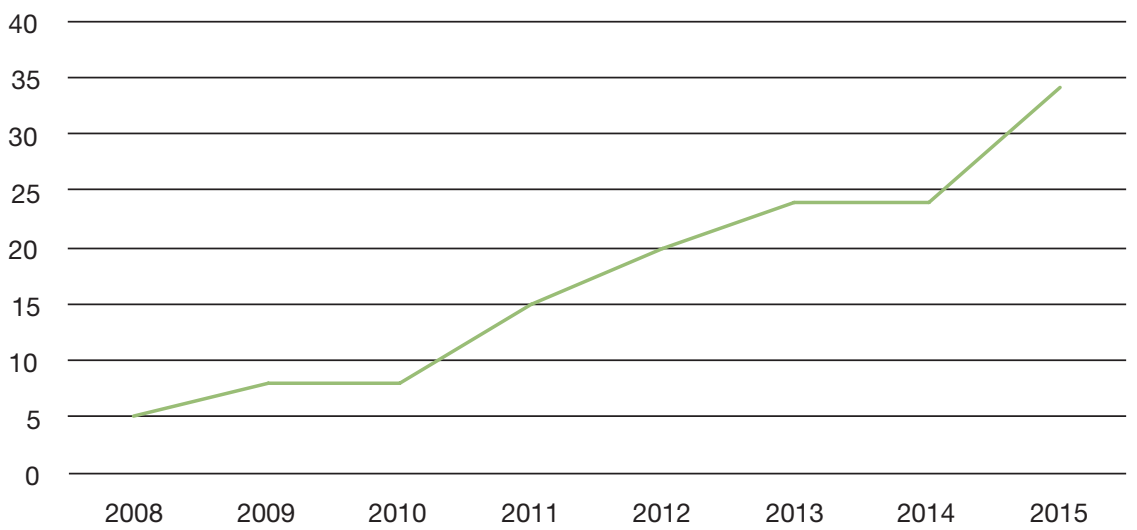

Fuente: elaboración propia con base en los datos de la Secretaría de Salud del Estado de Río Grande del Sur. Departamento de Acciones en Salud / DAS-RS, 2015.

Lo cierto es que la novedosa propuesta de trabajo sureña ha favorecido el vertiginoso incremento de los EABp en la región, que pasaron de 8 en el año 2010 a 34 en 2015. Se ha proporcionado atención al 60\% de la población que se encuentra en régimen cerrado de cumplimento de pena, porcentaje que arroja la cifra de 16.864 personas privadas de libertad. En el campo práctico, se han producido una serie de avances, como la reducción de la mortalidad, el aumento del acceso a los servicios sanitarios, el énfasis en la promoción de la

4. Por tanto, la política pública de salud de la población privada de libertad se encuentra bajo gestión directa de la Secretaria de Salud y se ejecuta en centros cuya responsable es la Secretaria de Seguridad Pública. Ambas secretarias están supeditadas al Gobierno del Estado de Río Grande del Sur. Ya los profesionales que trabajan en la salud dentro de prisiones están vinculados a la SUSEPE o a los municipios, pues estos últimos son los responsables del SUS. Como no podría ser de otra forma, el compromiso interinstitucional constituye una pieza clave para la ejecución de las acciones y de los cuidados en salud. 
salud y no solamente en la recuperación de la misma, la vigilancia epidemiológica y la detección y el tratamiento precoz de tuberculosis y de VIH/SIDA (Dotta-Panichi, 2014).

Paulatinamente, se ha producido la habilitación de los EABp en las prisiones de mujeres. De los 100 establecimientos existentes en nuestra región, en aproximadamente 73 hay reclusas, pero tan solo cuatro son exclusivamente femeninos: en la capital, el Instituto Penal Feminino de Porto Alegre y la Penitenciária Feminina Madre Pelletier; la recién construida Penitenciária Estadual Feminina de Guaíba, aproximadamente a 35 kilómetros de la capital, y el Presídio Estadual Feminino de Torres, con ubicación en el litoral del Estado, aproximadamente a 200 kilometros de Porto Alegre. Nótese que, de los dos establecimientos existentes en esta, la Penitenciária Feminina Madre Pelletier es la que recibe reclusas para el cumplimiento de pena en régimen cerrado.

Como no podría ser de otra forma, la interseccionalidad entre salud, mujeres y prisión da pie a desafíos de los más diversos órdenes. Un factor añadido es que, desde las instancias oficiales, no se dispone de datos sanitarios desglosados por sexos, escenario que imposibilita el conocimiento del perfil de las mujeres en situación de prisión en la región y el diseño de una política pública de atención a la salud centrada en sus necesidades. El proyecto La situación de las mujeres privadas de libertad y el soporte matricial en salud mental a los Equipos de Atención Básica $(E A B P)$ insertos en el sistema carcelario nace para hacer frente a esta laguna.

\section{Objetivos}

Se pretende conocer la situación psicosocial de las mujeres privadas de libertad en la cárcel de mujeres Madre Pelletier. Los objetivos específicos son:

1. Identificar las acciones y los servicios de salud implementados para las reclusas.

2. Cualificar el trabajo del EABp en funcionamiento en esta prisión.

3. Producir conocimiento científico que sirva de fundamento para el diseño de una línea de cuidado de atención integral a la salud de las mujeres privadas de libertad con recorte de género por parte de la Secretaría de Salud del Estado de Río Grande del Sur.

\section{Hipótesis de partida}

Dos son las hipótesis de partida del proyecto:

a) El trabajo del EABp desconoce las especificidades del encarcelamiento femenino.

b) El trabajo del EABp no se articula con los demás servicios existentes en el ámbito comunitario. 


\section{Método}

Se ha trabajado bajo la metodología de pesquisa acción exploratoria y etnográfica con el EABp en funcionamiento en la cárcel de mujeres Madre Pelletier. Para ello, se ha estructurado la investigación cualitativa en dos etapas: la primera se ha centrado en los grupos focales y la segunda, en el soporte matricial. Es importante observar que, al tratarse de una pesquisa acción pionera e interinstitucional de carácter eminentemente cualitativo, ganan cuerpo los significados atribuidos a las experiencias de los participantes y la perspectiva de mudanza de determinado problema diagnosticado a partir de su voz.

La técnica del grupo focal tiene por finalidad producir datos a partir de la interacción grupal. El intercambio de experiencias sobre determinada temática y la opinión del grupo participante en la técnica, considerada esta última a partir de opiniones, sentimientos y puntos de vista individuales, posibilita el aprender y pensar colectivamente (Kind, 2004; Gaskell, 2004). Por consiguiente, se ha diseñado un guión base, previamente discutido y consensuado con el grupo investigador, que permita conocer el EABp y su forma de trabajo, identificar las potencialidades y las fragilidades del mismo y, especialmente, visibilizar las expectativas en lo relativo al soporte matricial a realizar en un futuro próximo.

Se han ejecutado dos grupos focales de dos horas cada uno y se ha solicitado a todos los integrantes del EABp la participación en uno de ellos, pues puede no coincidir en el mismo día de trabajo en la prisión. Por tanto, la población investigada en los grupos focales han sido los profesionales de salud que componen el EABp de la prisión Madre Pelletier. Los criterios de inclusión han sido formar parte del EABp y manifestar interés en participar de la investigación.

Figura 2. Técnica del grupo focal

\begin{tabular}{|c|c|c|}
\hline \multicolumn{3}{|c|}{ Grupo focal } \\
\hline Participantes & Todos los que componen el EABp. & \\
\hline \multirow[t]{2}{*}{ Participación } & Grupo 1 & Grupo 2 \\
\hline & $\begin{array}{l}1 \text { asistente social } \\
1 \text { psicóloga } \\
1 \text { enfermera } \\
1 \text { dentista } \\
1 \text { médico } \\
1 \text { técnica de enfermería } \\
\text { Total: } 6 \text { personas }\end{array}$ & $\begin{array}{l}2 \text { enfermeras } \\
2 \text { técnicas de enfermería } \\
1 \text { médico psiquiátrico } \\
\text { Total: } 5 \text { personas }\end{array}$ \\
\hline Moderadora & \multicolumn{2}{|c|}{$\begin{array}{l}\text { Integrante del equipo investigador con formación específica en salud mental } \\
\text { colectiva y previamente capacitada en esta técnica. }\end{array}$} \\
\hline Local & \multicolumn{2}{|l|}{ Teatro de la prisión. } \\
\hline Duración & \multicolumn{2}{|l|}{2 horas. } \\
\hline Grabación & \multicolumn{2}{|l|}{ Sí. } \\
\hline
\end{tabular}

Fuente: elaboración propia. 
Los grupos se pusieron en marcha guiados por una moderadora integrante del equipo investigador, con formación específica en salud mental colectiva y con experiencia en esta técnica. Además, las actividades se realizaron en el espacio conocido como teatro: un local amplio disponible en la entrada de la prisión. La elección de esta zona se debió, principalmente, a la posibilidad de reunir a un mayor número de personas sin la necesidad de acompañamiento de una funcionaria de seguridad. Todos los integrantes del EABp participaron en la técnica y demostraron un gran interés en la construcción colectiva de conocimiento, ya que compaginaron su labor en la prisión de mujeres con otro trabajo en el sistema de salud de la comunidad o con el existente en la prisión de hombres.

A partir de los datos recogidos en los grupos, se inició la segunda etapa, principal propósito de la presente pesquisa. El soporte matricial consiste en un nuevo modelo de pensar y producir salud por medio de la permanente construcción de prácticas y conocimientos entre equipos sanitarios. Se dirige, pues, a la reforma de la organización y del trabajo en salud, y cuenta con una retaguardia especializada para que la usuaria del sistema sanitario (en el caso que nos ocupa, se trata de las mujeres reclusas) no se desvincule del equipo de referencia (en este caso, el EABp) (Dotta-Panichi et al., 2014; Campos y Domitti, 2007).

$\mathrm{Al}$ pretender contribuir a la mejora del trabajo del EABp, según su propia experiencia en la prisión, el soporte matricial está diseñado con cierta flexibilidad. En otras palabras, no se traza anticipadamente el camino para los resultados de la investigación (Costa y Paulon, 2012: 574). El equipo que ofrece soporte (en este caso, el equipo investigador) debe estar abierto a las demandas del equipo a matriciar (en este caso, el EABp), pues se trata de una relación en constante construcción y revisión. El soporte se ejecutó bajo el método Paideia, cuyo presupuesto es la construcción democrática del trabajo por medio de contratos y compromisos en constante revisión (Campos y Domitti, 2007).

Se consensuó con el EABp la selección de cuatro casos para la realización del soporte matricial a lo largo de seis meses. Asimismo, se convino que los 12 encuentros entre los equipos serían quincenales, de aproximadamente 2 horas cada uno. En lo relativo a los casos seleccionados, se optó por aquellos que el EABp consideraba de complejo manejo y entendían de primera necesidad revisar e innovar el trabajo ofrecido intramuros. Por tanto, los criterios de selección fueron su complejidad y los posibles resultados que se darían con la revisión e innovación del trabajo ofrecido intramuros.

$\mathrm{Al}$ tratarse de un estudio realizado en prisiones, el equipo matriciador era emitentemente interdisciplinar y estaba compuesto por investigadores con formación en Ciencias de la Salud, en particular Psicología y residentes en Salud Mental Colectiva, en Derecho y Trabajo Social. Los técnicos de la División de Salud de la SUSEPE contribuyeron a establecer la intersectorialidad inherente al proyecto.

Nótese que la segunda etapa de la investigación se estructuró bajo dos dimensiones complementarias: de soporte asistencial (apoyo y cuidado en 
salud) y técnico-pedagógica (apoyo a acciones educativas con el equipo). Para la discusión de los casos, se diseñó un guión entre el equipo matriciado y el matriciador. A fin de asegurar la fiabilidad de las informaciones y de los datos recogidos a lo largo de la pesquisa, los integrantes del EABp autorizaron la grabación de las actividades. Estas fueron literalmente trascritas a un documento formato Word, con lo que se dio inicio al análisis de contenido (Bardin, 1977). En este punto, cabe señalar que todas las personas que colaboraron con la pesquisa firmaron el consentimiento informado y participaron en ella de forma voluntaria.

A la SUSEPE, se le solicitaron los datos disponibles para la caracterización del perfil sociodemográfico y penal de las reclusas.

Figura 3. Metodología del soporte matricial

\begin{tabular}{ll}
\hline & \multicolumn{1}{c}{ Soporte matricial } \\
\hline $\begin{array}{l}\text { Equipo matriciado } \\
\text { Equipo matriciador }\end{array}$ & $\begin{array}{l}\text { EABp. } \\
\text { Equipo investigador multidisciplinar: Derecho, Trabajo Social y Ciencias de } \\
\text { la Salud, en particular Psicología y residentes en Salud Mental Colectiva. }\end{array}$ \\
Local & USBp y red de salud y servicios fuera de prisiones. \\
Frecuencia & Encuentros quincenales de 2 horas. \\
Extensión & 6 meses. \\
Grabación & Sí. \\
Acciones & Apoyo de 4 casos integrados con talleres de educación continuada en salud.
\end{tabular}

Fuente: elaboración propia.

\subsection{Delimitación social}

Profesionales que componen el EABp en funcionamiento en la cárcel de mujeres Madre Pelletier. Se seleccionó esta prisión porque abriga exclusivamente a mujeres que cumplen condena en régimen cerrado y porque cuenta con una unidad materno-infantil. Asimismo, se trata de una prisión geográficamente privilegiada, ya que se sitúa dentro del término urbano de la capital del Estado de Río Grande del Sur, la ciudad de Porto Alegre.

\subsection{Delimitación institucional}

El proyecto está a cargo del Área Técnica de Atención Integral a la Salud de las Personas Privadas de Libertad del Departamento de Acciones en Salud de la Secretaría de Salud del Estado de Río Grande del Sur (DAS-SES/RS). Cuenta, además, con la colaboración de la SUSEPE, la Escuela de Salud Pública (ESP), la Universidad Federal de Río Grande del Sur (UFRGS), la Fundación Escuela del Ministerio Fiscal (FMP) y del Instituto Andaluz Interuniversitario de Criminología de la Universidad de Sevilla/España (IAIC/US). Parte de la pesquisa se ha realizado conjuntamente con la Universidad Federal de Ceará (Kerr, 2011-actual) responsable de un proyecto de envergadura nacional sobre 
salud de la mujer reclusa y funcionarias de prisión para subsidiar la ya mencionada PNAMP. La referida pesquisa recoge la voz de las presas y funcionarias de prisión, y los resultados se encuentran en proceso de análisis.

\subsection{Delimitación temporal}

Se trata de una investigación bianual (de octubre de 2013 a octubre de 2015) y la etapa empírica tuvo lugar entre los meses de enero y agosto de 2015. Se consideró conveniente estructurar las etapas cualitativas en un período temporal lo más conciso posible, ya que la población carcelaria está en constante movimiento y el grupo investigador se adentraría en la rutina del EABp.

\subsection{Limitaciones e investigaciones futuras}

El presente estudio recoge la experiencia del EABp de apenas una cárcel de mujeres de un total de cuatro en funcionamiento en el Estado de Río Grande del Sur. Podrían surgir posibles limitaciones, bien vinculadas a las singularidades del trabajo ejecutado por los profesionales que integran dicho equipo, bien por las características de las mujeres reclusas atendidas por ellos. Además, la propia estructura del establecimiento Madre Pelletier, antiguo convento de monjas adaptado para el funcionamiento de una prisión, puede acarrear importantes limitaciones en razón de las diferencias que presenta cuando se compara con los demás centros existentes en la región. En cualquier caso, puede afirmarse que se ha llevado a cabo una primera aproximación al tema objeto de estudio. Se espera que las investigaciones futuras puedan contar con estudios más amplios, que incluyan todos los $\mathrm{EABp}$ en funcionamiento en las cárceles de mujeres en el sur de Brasil y estudios trasversales con los EABp existentes en las cárceles mixtas, e, igualmente, que se pueda desarrollar una pesquisa acción que tenga por propósito el diseño, la puesta en marcha y la evaluación de programas en prisiones.

\section{Resultados}

\section{1. ¿Quiénes son las reclusas que se encuentran en la cárcel Madre Pelletier?}

Las reclusas en la cárcel de mujeres Madre Pelletier son, en su mayoría, brasileñas (un 99\%), jóvenes (un 61\% tiene 34 años o menos), de color de piel autodeclarada blanca (un 63\%), con formación escolar precaria (un 59\% afirmó ser analfabeta, alfabetizada o poseer enseñanza primaria incompleta), solteras (un 61\%) y que se encuentran encarceladas por un delito de tráfico de drogas (un 96\%). La prisión tiene capacidad para recibir hasta 239 personas que se encuentran a la espera de juicio o condenadas a cumplir una pena privativa de libertad en régimen cerrado. Actualmente, alberga el $13 \%$ del total de reclusas del Estado de Río Grande del Sur.

El perfil de las reclusas en la cárcel Madre Pelletier coincide, por lo general, con el perfil existente en las demás cáceles de la región. Un análisis más 
Tabla 1. Perfil y situación penal de las mujeres privadas de libertad en el Estado de Río Grande del Sur (RS) y en la cárcel Madre Pelletier (PFMP)

\begin{tabular}{|c|c|c|c|c|}
\hline \multirow[b]{2}{*}{ Variable } & \multicolumn{2}{|c|}{ RS } & \multicolumn{2}{|c|}{ PFMP } \\
\hline & $n$ & $\%$ & $n$ & $\%$ \\
\hline Total de reclusas & 1.716 & 100 & 230 & 13,4 \\
\hline \multicolumn{5}{|l|}{ Escolaridad } \\
\hline Analfabeta & 36 & $2,09 \%$ & 3 & $1,30 \%$ \\
\hline Alfabetizada & 39 & $2,27 \%$ & 5 & $2,17 \%$ \\
\hline Enseñanza primaria incompleta & 976 & $56,87 \%$ & 128 & $55,65 \%$ \\
\hline Enseñanza primaria completa & 198 & $11,53 \%$ & 24 & $10,43 \%$ \\
\hline Enseñanza secundaria incompleta & 218 & $12,70 \%$ & 29 & $12,60 \%$ \\
\hline Enseñanza secundaria completa & 201 & $11,71 \%$ & 35 & $15,21 \%$ \\
\hline Enseñanza superior incompleta & 34 & $1,98 \%$ & 6 & $2,60 \%$ \\
\hline Enseñanza superior completa & 12 & $0,69 \%$ & 0 & $0,00 \%$ \\
\hline No informado & 2 & $0,11 \%$ & 0 & $0,00 \%$ \\
\hline \multicolumn{5}{|l|}{ Edad (en años) } \\
\hline 18 a 24 & 267 & $15,55 \%$ & 50 & $21,73 \%$ \\
\hline 25 a 29 & 346 & $20,16 \%$ & 48 & $20,86 \%$ \\
\hline 30 a 34 & 346 & $20,16 \%$ & 44 & $19,13 \%$ \\
\hline 35 a 45 & 487 & $28,37 \%$ & 62 & $26,95 \%$ \\
\hline 46 a 60 & 245 & $14,27 \%$ & 24 & $10,43 \%$ \\
\hline Más de 60 & 25 & $1,45 \%$ & 2 & $0,86 \%$ \\
\hline \multicolumn{5}{|l|}{ Color de piel/etnia } \\
\hline Amarilla & 11 & $0,62 \%$ & 0 & $0,00 \%$ \\
\hline Blanca & 1.097 & $63,92 \%$ & 147 & $63,91 \%$ \\
\hline Indígena & 15 & $0,87 \%$ & 2 & $0,86 \%$ \\
\hline Negra & 190 & $11,07 \%$ & 42 & $18,26 \%$ \\
\hline Parda & 402 & $23,42 \%$ & 39 & $16,95 \%$ \\
\hline \multicolumn{5}{|l|}{ Estado civil } \\
\hline Casada & 156 & $9,09 \%$ & 12 & $5,21 \%$ \\
\hline Con pareja de hecho & 502 & $29,25 \%$ & 54 & $23,47 \%$ \\
\hline Divorciada & 33 & $1,92 \%$ & 9 & $3,91 \%$ \\
\hline Separada & 51 & $2,96 \%$ & 7 & $3,04 \%$ \\
\hline Soltera & 920 & $53,61 \%$ & 142 & $61,73 \%$ \\
\hline Viuda & 54 & $3,14 \%$ & 6 & $2,60 \%$ \\
\hline \multicolumn{5}{|l|}{ Nacionalidad } \\
\hline Brasileña & 1.708 & $99,53 \%$ & 229 & $99,56 \%$ \\
\hline Extranjera & 8 & $0,47 \%$ & 1 & $0,43 \%$ \\
\hline \multicolumn{5}{|l|}{ Reincidencia } \\
\hline Reincidentes & 901 & $52,50 \%$ & 105 & $45,65 \%$ \\
\hline No reincidentes & 815 & $47,49 \%$ & 125 & $54,34 \%$ \\
\hline \multicolumn{5}{|l|}{ Delito principal } \\
\hline Tráfico de drogas & 1.635 & $95,27 \%$ & 223 & $96,95 \%$ \\
\hline
\end{tabular}

Fuente: elaboración propia con base en los datos de la SUSEPE (julio de 2015). 
Gráfico 2. Población de hombres y mujeres en prisión en el Estado de Río Grande del Sur

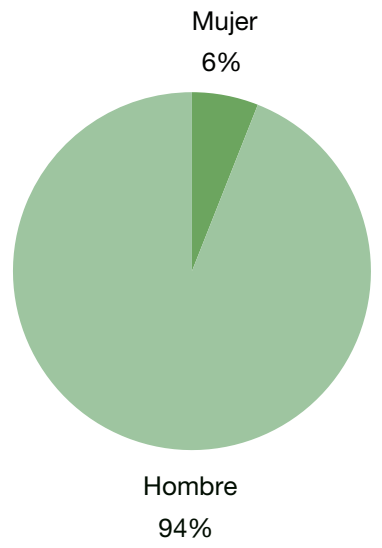

Fuente: elaboración propia con base en los datos de la SUSEPE (julio de 2015).

detallado, no obstante, revela un diferencial apreciable: el índice de reincidencia. El 52\% de las reclusas en el estado son reincidentes, mientras que en la cárcel Madre Pelletier este índice es del 45\%. Una posible explicación para esa diferencia puede estar relacionada con el menor grado de peligrosidad de las reclusas que se encuentran en la prisión de la capital, conocida por ser la "puerta de entrada» de las presas provisionales y/o que fueron condenadas exclusivamente por tráfico de drogas. De hecho, según los datos complementarios de la SUSEPE, se estima que aproximadamente el 60\% de las reclusas en la cárcel Madre Pelletier aguarda decisión judicial y que, si bien el $96 \%$ tiene como delito principal el tráfico de drogas, aproximadamente el 80\% está siendo acusada o fue condenada exclusivamente por este delito.

Cuando se compara con la población reclusa masculina, la población femenina es residual, ya que, del total de personas presas en el sur, tan solo el $6 \%$ son mujeres.

\section{2. ¿Cómo trabaja y quién compone el EABp?}

Desde 2011, se encuentra en pleno funcionamiento una UBSp dentro de la prisión Madre Pelletier. Se trata de un servicio de salud para mujeres reclusas pionero en el ámbito del SUS y que funciona mediante un convenio con el municipio de Porto Alegre, concretamente con el Hospital Vila Nova.

El EABp que trabaja en la UBSp está formado por un total de 11 profesionales. Parte de ellos son contratados por el municipio de Porto Alegre por medio de un convenio: dos enfermeras, una técnica de enfermería, dos médicos clínicos generales, una médica ginecóloga y un médico psiquiatra. Algunos de estos profesionales actuaban en el susodicho Hospital Vila Nova, y voluntariamente se apuntaron al trabajo en prisiones; otros armonizan su labor con el 
Figura 4. EABp de la cárcel Madre Pelletier

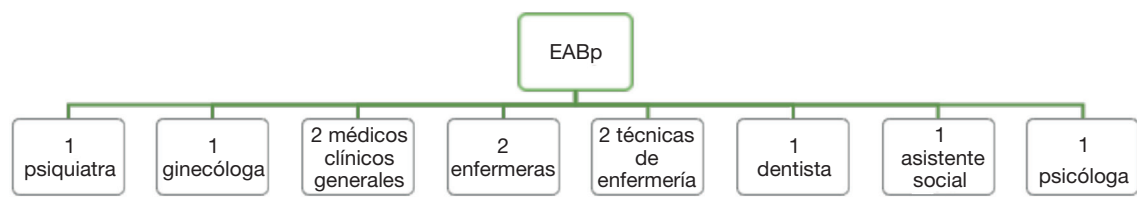

Fuente: elaboración propia.

establecimiento penitenciario exclusivo de hombres y/o destinado al cumplimiento de pena en régimen menos gravoso. Los demás miembros del equipo son funcionarios de la SUSEPE. Concretamente, un dentista, una psicóloga, una técnica de enfermería y una asistente social que actúan solo en prisiones.

La UBSp se ubica en la segunda planta de la cárcel y su puerta principal da acceso al patio ${ }^{5}$. Nada más entrar en ella, se vislumbra la estancia de espera y una entrada para la sala de acogida. Además, está compuesta por otros pequeños recintos destinados a la atención por parte de la enfermera, el médico, el dentista y la psicosocial.

El acceso de las reclusas a la UBSp está organizado según los módulos existentes en la prisión. Para ello, debe informar al jefe de seguridad de su módulo de la necesidad de dirigirse hasta la Unidad de Salud, lo que suelen hacer sin acompañamiento de un funcionario de seguridad hasta el servicio. A día de hoy, reciben atención del EABp aproximadamente 220 reclusas.

Diariamente, se ofertan consultas médicas y odontológicas, distribución de medicación controlada y tratamiento directamente observado ${ }^{6}$. Los atendimientos psiquiátricos se prestan todos los viernes, de las 8 de la mañana a las 5 de la tarde.

La UBSp también es responsable de la acogida inicial de aquellas que ingresan en el sistema. Se trata de un cuestionario en el cual se preguntan, por ejemplo, el nombre de los padres, la existencia de hijos, la práctica o no de relaciones sexuales y el motivo de la prisión, acompañado de la realización de una batería de pruebas, como el test rápido de $\mathrm{VIH}$, sífilis y hepatitis $\mathrm{B}$ y C. Además, se explica a la nueva interna los días de atención disponibles para su módulo.

Esporádicamente, se organizan actividades en el formato "mutirão», es decir, actividades realizadas en fechas muy concretas y en bloque para todas las reclusas. Cítese como ejemplo las mamografías realizadas conjuntamente con el Instituto del Cáncer de Mama (IMAMA) en el mes de octubre.

5. Para acceder a la UBSp, es necesario pasar por el control de seguridad existente en la entrada de la prisión: dos puertas de apertura manual, siendo una de ellas vigilada por funcionarios de seguridad que controlan todas las entradas y salidas de la cárcel.

6. El tratamiento directamente observado, más conocido como TDO, se refiere al acompañamiento del técnico de salud para la ingestión de la medicación prescrita a la usuaria. 


\subsection{Género, salud y prisión. Potencialidades y fragilidades del trabajo interseccional}

El recurso a la metodología cualitativa ha permitido mejorar la valoración de los profesionales del EABp sobre su trabajo dentro de prisiones, las potencialidades y las fragilidades del mismo, así como visibilizar las expectativas en lo relativo al soporte matricial a realizar en un futuro próximo.

Ha sido posible identificar tres categorías tras el análisis de contenido de los grupos focales. Concretamente: prisión, salud y género. Teniéndose en cuenta que se acordó con los profesionales participantes el anonimato de sus opiniones, se les atribuyó un número antecedido de la letra P de profesional (P.1 para profesional número uno, P.2 para profesional número dos y así en adelante).

\section{a) Prisión}

En lo relativo a la prisión, ha sido posible identificar dos categorías intermedias: las especificidades del encarcelamiento de mujeres y la dificultad de organizar el proceso de trabajo del EABp. En el primer punto, vislumbran la necesidad de atención diferenciada, el abandono y su sufrimiento en prisión:

[... ¡ ¡es un perfil diferente, verdad? La reclusa femenina del recluso varón. La mujer necesita de más atención [...]. (P.1)

[...] por el hecho de estar encerradas, detenidas, reclusas, todas las quejas se multiplican por diez veces. El dolor es más intenso, la ansiedad es más intensa. Entonces, nosotros lidiamos con cosas muy tensas, depresiones graves, ansiedades refractarias a la medicación, porque es un ambiente ansiogénico ya de salida [...]. (P.2)

[...] las visitas prometen y no vienen. Ellas se quedan solas por años [...]. (P.3)

Además, relatan que la conducta delictiva de las reclusas, en su gran mayoría, se vincula a la conducta de los compañeros sentimentales o de los hijos que se encuentran en prisión, que les solicitan ingresar con droga en los días de visitas. El relato que se puede leer a continuación ejemplifica lo expresado por el grupo:

Mi marido fue a la cárcel [...] estábamos juntos, también me detuvieron y no era mía [refiriéndose a la droga]. Todos los días nos dicen esto. (P.3)

Sobre las dificultades de organizar el proceso de trabajo, se denota la necesidad de una labor pionera en prisiones y de trabajar en redes intramuros y extramuros. Los relatos de los profesionales revelan los beneficios del trabajo en grupos y de diseñar una cualificación específica en la temática, partiendo de las prácticas desarrolladas por ellos:

Cuando comenzamos aquí en 2011 nadie nos enseñó nada, fuimos «tanteando y conduciendo el barco». Hoy creamos nuestras rutinas con base en la reali- 
dad, así que estamos siempre abiertos a la discusión y creo que es así, enseñar caminos e intentar ayudar a la gente, pues muchas veces, por estar aquí solos, te agotas $[\ldots]$. (P.2)

Pienso que una integración de nuestro equipo para planear cosas, como grupos [...] creo que el recurso es este: el recurso humano [...]. (P.1)

Enmarcan el reto que ha representado para los demás sectores de la prisión el inicio de un servicio novedoso intramuros y desarrollado por profesionales provenientes de la salud, que también actúan fuera de prisiones. La ausencia de funcionarios de seguridad en los alrededores de la UBSp y, al tiempo, la comprensión de en qué consiste una labor diferenciada en salud, en particular relacionada con el cuidado en salud mental, fueron y siguen siendo objeto de constante lucha. Véanse los siguientes relatos:

[...] pienso que una cuestión mala es la ausencia de seguridad, a veces no hay como. Entonces, ¿cómo se trabaja? [...]. (P.1)

Yo me quedo sola, cierro la puerta y la reclusa [...] ella hablará de cosas sobre las que no hablaría si hubiera un guardia allí [...]. (P.4)

No pocas veces, la atención y el cuidado en salud quedan supeditados a cuestiones de seguridad ${ }^{7}$. La salud del trabajador, pues, irrumpe como un constante reto en razón de la sobreimplicación con el trabajo intramuros:

Estamos siempre atendiendo, atendiendo, atendiendo, pero no hay ningún programa; ningún profesional que me escuche, que me cuide [...]. Convivir con ellas intramuros también desestabiliza nuestra estructura emocional y vemos problemas en el hacer, las dificultades profesionales, el número de profesionales para hacer este trabajo, de interés también, de tiempo [...] Yo me siento un poco, como profesional, me siento impotente. Porque yo aconsejo, escucho $[\ldots]$ por más que me involucre[...] va más allá de mi trabajo $[\ldots]$ no puedo ofrecer otras cosas [...]. (P.2)

En lo que se refiere a la necesidad de trabajar en redes intramuros y extramuros, revelaron que los equipos de salud que se encuentran en funcionamiento en la comunidad no absorben los casos enviados por el EABp. Entre las razones aducidas, se resaltaba la ausencia y/o la tardanza de atención especializada para aquellos que se encuentran en prisión, en particular para el tratamiento de casos graves de adicción. Revelan, por ejemplo, que el local de referencia para estos casos es el Instituto Psiquiátrico Forense (IPF), local destinado al cumplimento de medidas de seguridad, y no el Centro de Aten-

7. Sirve de ejemplo la huelga de los funcionarios de seguridad para conseguir mejores condiciones de trabajo que afectó a los servicios rutineros de la prisión y a la puesta en marcha de los grupos focales. 
ción Psicosocial (CAPS AD) existente en la comunidad ${ }^{8}$. Véanse los siguientes relatos:

[...] acogemos a la reclusa de la mejor manera posible, sin internamiento, pero precisando de internamiento $[\ldots]$ no tienes soporte para encaminarla, ¿entiendes? Si ella necesita de una internación, no hay como hacer la guarda en el hospital [...] hoy la normativa es para encaminar al CAPS y no más al IPF. Esto es lo que debería ocurrir [...]. (P.1)

Asimismo, cuentan que los servicios comunitarios desconocen las situaciones de vulnerabilidad de las reclusas cuando llega su excarcelación, en particular las vinculadas con el tráfico de drogas:

[...] nuestras pacientes son aves migratorias; hoy ella está en la residencia tal, que tiene un callejón, que tiene un punto de tráfico, ahí ella migra para otra dirección, los teléfonos de la familia cambian mucho [...]. (P.2)

[...] hace falta una preparación de la red [...] en la atención a las prisiones; del sujeto en prisión [...] para nosotros, la mayor dificultad es redirigirlas a la red $[\ldots]$ y ella $[$ la reclusa] cambiar de residencia $[\ldots]$ (P.1)

La dificultad del trabajo en redes no se refiere solo al servicio de salud, sino también a la escasez de recursos y a la estructura y articulación con los demás sectores de la prisión Madre Pelletier o con el establecimiento responsable del cumplimento de la pena en un régimen menos gravoso. Según el grupo, no era infrecuente que las reclusas manifestasen "predilección" por permanecer encerradas antes que cumplir pena en un régimen menos gravoso, aunque este ofrezca cuotas de libertad, en razón de la estructura que la cárcel ofrece cuando se compara con estos establecimientos:

[...] prefieren quedarse aquí $[\ldots]$ paran de trabajar, paran todo, con todo lo que tienen aquí [...] prefieren salir de aquí a la calle [...]. (P.4)

Particularmente, aquellos que ya ejercieron actividad profesional en otros establecimientos penales puntualizan que el trabajo en redes con la salud comunitaria o con otras estructuras del Sistema de Justicia podría desarrollarse con mayor intensidad en el momento de la excarcelación. Consideran, además, que la ausencia de apoyo tiene relación directa con los índices de reincidencia. Se reafirmó la necesidad de actuar en el momento de la excarcelación:

Moderadora: ¿Qué hace falta?

P.2: Creo que la acogida, una red, para cuando ella salga en libertad.

P.1: Exactamente.

8. Los llamados Centro de Atenção Psicossocial Álcool e Drogas, más conocidos como CAPS $\mathrm{AD}$, son servicios específicos para el cuidado y la atención integral y continuada a las personas con necesidades provocadas por el consumo de alcohol, de crack y de otras drogas. 
P.4: Mitad reincide[...] y en este tiempo ella no recibe atención en ningún lugar.

\section{b) Salud}

En lo relativo a la categoría salud, se identificaron dos categorías intermedias: significado de salud y salud mental. Sobre el primer punto, los relatos de los profesionales enlazan salud con calidad de vida y bienestar físico y psíquico y, por consiguiente, cómo las categorías descritas en el apartado anterior - falta de estructura para la ejecución de la pena y servicios comunitarios - afectan a la extensión de su contenido:

[...] salud tiene que ver con la calidad de la prevención. Una situación de calidad de vida en las circunstancias que la persona está viviendo. Creo que hay que dar calidad [...]. (P.1)

[...] calidad de vida es salud bucal [...] muchas no tienen dientes para comer [...] mover el cuerpo, sea trabajando, con deporte, sea con alguna otra cosa [...] salud es equilibrio físico y psíquico [...] para mejor calidad de vida, para lograr cumplir la pena [...] tumbadas mirando el techo, están solo trabajando la cabeza para volverse enfermas [...]. (P.4)

En este contexto, el surgimiento y/o el agravamiento de enfermedades aparecen íntimamente vinculados al ocio. En particular, a la ausencia de actividades físicas y de trabajo:

[...] toda y cualquier actividad que rompa con la rutina de ellas disminuye la ansiedad y muchas veces repercute en la amplia prescripción de medicamentos: disminuye el uso de medicamentos [...]. (P.5)

[...] la necesidad de actividad laboral, no importa cuál sea, por lo menos están moviéndose, no están en la celda mirando al techo, solo tienen una forma de no pensar en lo que está ocurriendo fuera, es haciendo alguna cosa [...] Hace mucho tiempo, antiguamente, había juegos de balonmano aquí [...] esto es muy importante hablándose de salud [...] cursos de peluquera, maquillaje [...] es grande el número de reclusas que empezaron a tomar medicamentos controlados después que la empresa cerró. (P.4)

El grupo hace hincapié no solo en el impacto que el cese de las actividades laborales en la prisión tuvo en la salud de las reclusas, sino también sobre el notorio incremento del uso de medicación controlada?.

Sobre la salud y su relación con la estructura que las reclusas poseen fuera de prisiones, se ponen de manifiesto las vulnerabilidades que son consecuencia de la ausencia de servicios públicos básicos:

9. El Gobierno había autorizado el funcionamiento de una empresa dentro de la prisión, pero los problemas con el pago de los sueldos de las reclusas derivaron en el cierre de la misma sin el reemplazo de las actividades. 
[... también la estructura básica en servicios públicos donde viven, tratamiento. Esto también influencia en la salud [...] (P.2)

Ahora bien, la expresión más evidente de las consecuencias entre el significado de salud asumido por el grupo y de la falta de estructura intramuros y extramuros se externaliza en el diseño de una línea de cuidado individual solamente con algunas reclusas:

[...] nosotros trabajamos con línea de cuidado individual. Tu acuerdas, muchas veces, con una, pero con otra no puedes hacer lo mismo porque no lo cumplirá [...]. (P.1)

En otras palabras, no logran desarrollar un proyecto terapéutico singular con incidencia en distintos aspectos de la vida de la mujer dentro o fuera de prisiones. Al tiempo, relatan que las demandas colectivas de la prisión son un tanto invisibles. Estas últimas eran resueltas por la participación de reclusas reconocidas como "promotoras de salud» o «multiplicadoras de salud», que llevaban las demandas de cada módulo al $\mathrm{EABp}^{10}$. No obstante, tras su puesta en libertad, no se dio continuidad a la actividad.

[...] las promotoras de salud era algo muy bueno. Escuchas el colectivo. (P.1)

[...] me acuerdo que, en la época, la reclamación eran los frijoles. Ahí trajimos una reclusa representante de la cocina y la nutricionista. Se dieron sugerencias, por ejemplo, que los frijoles estaban muy duros, que eran prácticamente crudos, que no lograban comerlos [...]. (P.2)

Llegados a este punto, es la salud mental la que aparece como la demanda principal y más compleja del EABp:

[...] las cuestiones de salud mental, las demandas de salud mental son las más emergentes en las atenciones, de un modo general [...]. (P.2)

[...] en cuanto a la parte física, ellas son acompañadas por médicos clínicos, tienen una agenda $[\ldots]$ tienen dentista, ginecóloga-obstetra. De la parte psicológica, tienen el psiquiatra y el psicólogo [...]. En este sentido, pienso yo, tienen cobertura y están bien atendidas. Está el otro lado de la moneda [...] la salud mental, en lo que se refiere a las relaciones. No sabría responder en qué nivel de salud están ellas en cuanto a las relaciones entre ellas [...]. (P.5)

Aquí se revelan dos perspectivas: de una parte, la medicalización y el tratamiento; de otra, la acogida y la movilización selectiva del EABp.

En referencia a la medicalización y al tratamiento, fueron observadas las

10. El proyecto de formación de mujeres privadas de libertad como multiplicadoras de salud en prisión tuvo lugar en el año 2012. 
dificultades de adhesión al tratamiento cuando se comparaba con la población masculina, así como la sobremedicación y el uso de medicamentos como moneda de cambio dentro de la prisión:

[...] yo trabajo en la cárcel de hombres. Aquí en la cárcel de mujeres hay una diferencia que es la adhesión al tratamiento. Los hombres son más tolerantes a los efectos colaterales de las medicaciones, por ejemplo. Las mujeres toman un antidepresivo que seca la boca y ya no lo quieren más, porque la lengua queda seca $[\ldots]$ los hombres entran en ajustes, ajuste de la dosis, asocian a otra medicación [...]. (P.4)

[...] Diazepam es un problema aquí, porque, como proporciona bienestar, reduce la ansiedad, les gusta tomar esta medicación. Es necesario tener mucha atención para lo que estoy dando a una persona: usar de forma recreacional, para pasarlo bien, o realmente es porque lo necesita [...]. (P.5)

[...] trabajamos con una población con muchas adicciones, desde la drogodependencia, el alcohol o la adicción a medicamentos. Aquí Diazepam es una gran adicción, no aceptan cambiar por otro medicamento, por dependencia, por moneda de cambio. No hay como afirmar esto, pero es así, es una dificultad también [...]. (P.2)

[...] el medicamento es la libertad [...]. (P.3)

Nótese que parte de los profesionales manifestaron sorpresa y frustración cuando uno de los compañeros reveló que, a día de hoy, se solicitan 6.000 comprimidos de Diazepam ${ }^{11}$ para 100 presas en la cárcel Madre Pelletier.

En términos de acogida y de movilización selectiva, el EABp es entendido como "puerta de entrada" para cuestiones de salud mental. En concreto, las quejas clínicas frecuentemente están vinculadas a factores emocionales, siendo la escucha la principal forma de acogida. No obstante, la movilización del equipo de salud y consecuente posibilitad de derivación a otros servicios está relacionada con el tiempo que la reclusa permanece en prisión. Por tanto, el acceso a la atención no garantiza el posterior tratamiento en toda su extensión. Véanse algunos relatos:

[...] ellas acuden por otros motivos [...] es la depresión que reacciona a sintomatología anterior; es bien característico [...]. (P.2)

Hay que saber cuánto tempo se quedarán aquí para ir a buscar la red [...]. (P.4)

Acogida, escucha. Y después encaminamos para dónde se pueda [...]. (P.1)

Es más, al profundizar el debate sobre salud mental, cuestiones que en principio se consideraban irrelevantes, ganaron gran trascendencia para el grupo.

11. Se trata de un ansiolítico, relajante muscular y anticonvulsivante usado en el tratamiento de ansiedad, agitación y espasmos musculares. 


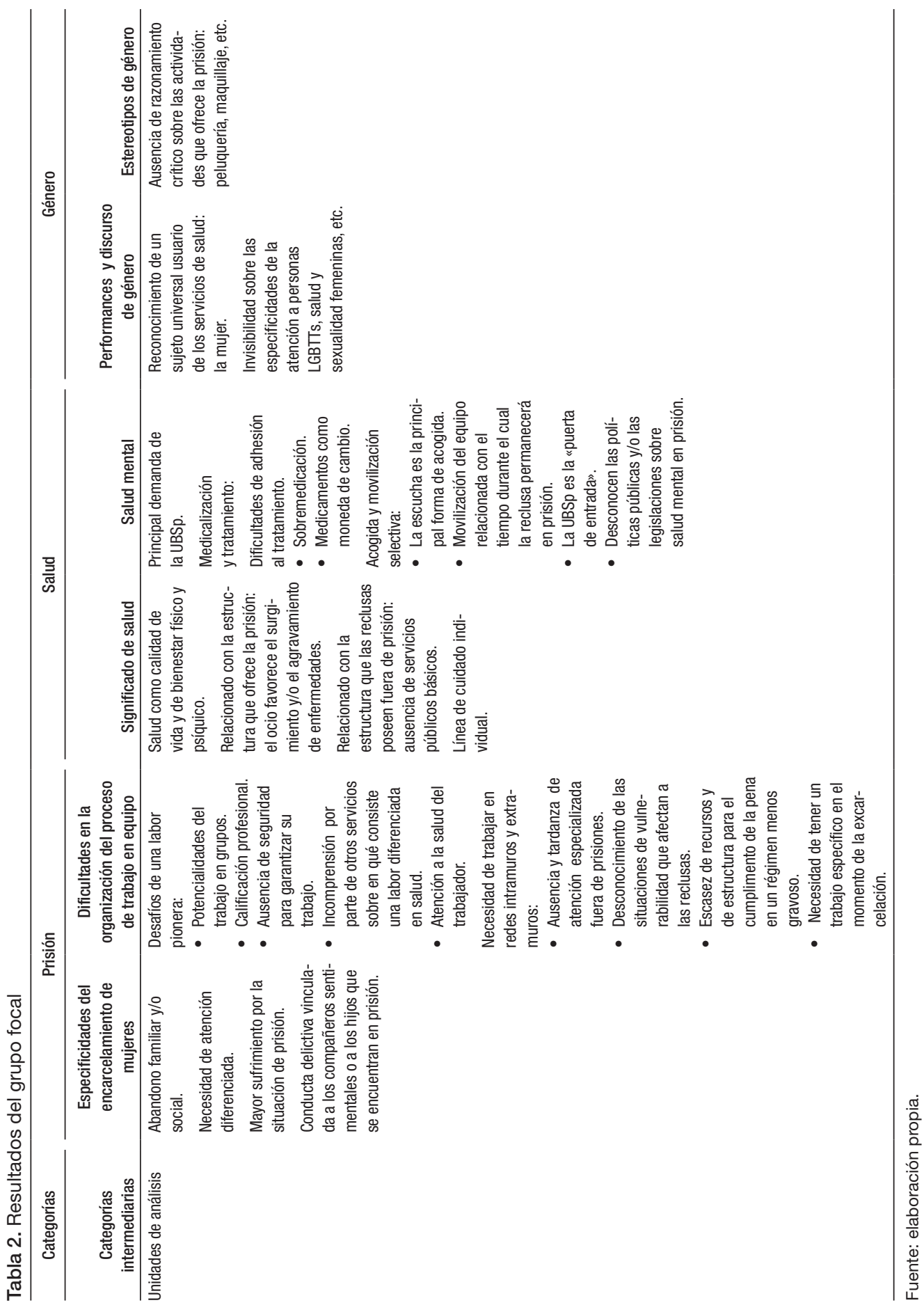


Concretamente, testificaron que las reclusas acuden a la UBSp por dolor de cabeza, náuseas, vómitos, diarrea, insomnio, ansiedad, depresión y, especialmente, para charlar; para hablar de las preocupaciones con el mundo exterior, como, por ejemplo, los hijos. Esta realidad parece deberse, en gran medida, al vínculo que los profesionales de salud lograron establecer con las mujeres y que fueron expresados en términos como confianza, seguridad y apoyo. Piensan que realmente la UBSp es la "puerta de entrada" para cuestiones de salud y otros problemas de la prisión:

Ella viene aquí porque el acceso es más fácil [...] llega primero aquí [...]. (P.2)

Ahora bien, al ser cuestionados sobre las políticas públicas y/o sobre las legislaciones sobre salud mental en prisión, la respuesta fue unánime y contundente:

¡No conozco! (P.5)

\section{c) Género}

La tercera categoría identificada fue el género, que, a su vez, confirmó la existencia de categorías intermedias: performances y discurso de género, de una parte; estereotipos de género, de otra parte.

El grupo percibe un sujeto universal usuario de los servicios de salud -la mujer-, y no demuestra razonamiento crítico desde una perspectiva de género, como, por ejemplo, las actividades destinadas a ellas:

[...] en 2013, se desarrollaron cursos de peluquería, maquillaje, artesanía, bisutería, cocina, costura [...]. (P.1)

[...] estos son muy buenos. ¡Ellas están profesionalizándose! (P.4)

La reflexión sobre estas cuestiones aflora de forma excepcional:

Lo ideal son trabajos que le den autonomía en la calle [...]. (P.1)

Nótese que cuestiones como las especificidades de la atención a personas LGBTT, la problematización de la salud y de la sexualidad femeninas o la ausencia de visitas íntimas y su impacto para la salud parecen quedar relegadas a un segundo plano. De hecho, en ningún momento salieron a la luz en los diálogos con el EABp.

\subsection{Soporte matricial. Análisis de casos y educación continuada}

A partir de las categorías establecidas en los grupos focales, y con el declarado propósito de contribuir a la mejora del trabajo del EABp, se diseñó el soporte matricial a cuatro casos. Al mismo tiempo, se ofreció la posibilidad de realizar acciones formativas con el equipo. Por tanto, esta etapa se estructuró bajo dos dimensiones complementarias: de soporte asistencial (apoyo y cuidado en salud) y técnico-pedagógica (apoyo a acciones educativas con el equipo). 
La elección de los casos se consensuó entre el EABp y el equipo que actuaría como matriciador (equipo investigador), teniendo en cuenta los posibles resultados que se darían con la revisión y la innovación del trabajo ofrecido intramuros. Si se toma en cuenta que el EABp atiende aproximadamente a 220 reclusas, la muestra de cuatro casos puede parecer poco representativa a primera vista. No obstante, como se ha afirmado en otro momento, el soporte matricial tiene por foco el proceso de transformación de las prácticas en salud. Más que el tamaño de la muestra, la importancia de trabajar con los casos seleccionados está en que reúnen, según la voz del EABp, una serie de problemáticas diagnosticadas como frecuentes en prisión y constituyen un verdadero desafío para aquellos profesionales habituados al trabajo en salud extramuros. De hecho, el soporte ha derivado en una serie de acciones entre el EABp y la red comunitaria de servicios.

El análisis de los casos ha revelado el abanico de factores de vulnerabilidad de las reclusas, tanto antes como durante su estancia en prisión. A saber:

- Múltiples experiencias de victimización: violaciones en la infancia y en la adolescencia, violencia por parte del compañero íntimo, pobreza extrema, abandono familiar, residentes en la calle, portadoras de VIH y enfermedades mentales graves, entre otras.

- Estilo de vida autodestructivo: graves problemas de adicción, especialmente crack y cocaína, e ideación suicida.

- Invisibilidad de sus condiciones de salud durante el aprisionamiento y/o en la excarcelación: reclusas en situación de salud muy débil cumpliendo penas largas en régimen cerrado o que se encontraban próximas a la excarcelación y desconocían los servicios de salud de su región.

- Invisibilidad de las cuestiones de género: transexualidad y salud reproductiva, por ejemplo.

Consiguientemente, las estrategias de intervención priorizaron la producción del cuidado de salud en redes. Concretamente, la articulación del EABp con la red de salud disponible en la comunidad y el sistema de justicia penal. Se destaca la articulación con el Programa Salud de la Familia, CAPS AD y Red de Atención Psicosocial (RAPS) ${ }^{12}$, así como el contacto y la discusión de los casos con el equipo psicosocial del Tribunal de Justicia y del juzgado responsable de la ejecución de la pena.

Por último, a partir de las problemáticas emergentes en el trabajo de campo, se desarrollaron talleres de educación continuada en salud acerca de las temáticas de género y un proyecto terapéutico singular. El objetivo no era otro que cualificar la práctica del EABp para la producción del cuidado integral en salud.

A continuación, se describen detalladamente los resultados alcanzados por medio del soporte matricial.

12. La información detallada sobre estos servicios y programas puede ser encontrada en: http:// portalsaude.saude.gov.br/ 
Tabla 3. Resultados del soporte matricial

\begin{tabular}{|c|c|c|c|}
\hline Dimensiones & $\begin{array}{r}\text { Soporte } \\
\text { (apoyo y cuida }\end{array}$ & $\begin{array}{l}\text { sistencial } \\
\text { (do de la salud) }\end{array}$ & $\begin{array}{l}\text { Soporte técnico- } \\
\text { pedagógico } \\
\text { (apoyo a acciones } \\
\text { educativas) }\end{array}$ \\
\hline $\begin{array}{l}\text { Diagnóstico e } \\
\text { intervención }\end{array}$ & $\begin{array}{l}\text { Principales factores } \\
\text { de vulnerabilidad } \\
\text { antes y durante el } \\
\text { encarcelamiento }\end{array}$ & $\begin{array}{l}\text { Acciones conjuntas entre } \\
\text { el EABp y el equipo matriciador }\end{array}$ & $\begin{array}{l}\text { Educación continuada } \\
\text { en salud }\end{array}$ \\
\hline Caso 1 & $\begin{array}{l}\text { Abandono y negligencia familiar: } \\
\text { residió en la calle y posterior- } \\
\text { mente en casa de acogida. } \\
\text { Usuaria de drogas: crack. } \\
\text { Enfermedades diagnosticadas } \\
\text { en prisión: toxoplasmosis y } \\
\text { sífilis. } \\
\text { Edad: } 20 \text { años. } \\
\text { Maternidad: bebé de } 5 \text { meses } \\
\text { que la acompaña en prisión. } \\
\text { Compañero: en prisión. } \\
\text { Red de apoyo actual: suegra, } \\
\text { que ya estuvo en prisión. } \\
\text { Delito: tráfico de drogas. } \\
\text { Se encuentra próxima a la } \\
\text { excarcelación. }\end{array}$ & $\begin{array}{l}\text { Trabajo para mejorar el vínculo } \\
\text { entre la reclusa y el hijo. } \\
\text { Acciones para mejorar el auto- } \\
\text { cuidado de la reclusa. } \\
\text { Dificultad para articular los ser- } \\
\text { vicios comunitarios, en razón del } \\
\text { tráfico de drogas en la región. } \\
\text { Articulación con el Programa } \\
\text { Salud de la Familia ejecutado en } \\
\text { el local donde reside la suegra. } \\
\text { La suegra probablemente asu- } \\
\text { mirá la guardia del niño hasta la } \\
\text { excarcelación de la reclusa. } \\
\text { Visita domiciliar de acompaña- } \\
\text { miento. }\end{array}$ & $\begin{array}{l}\text { Taller sobre género. } \\
\text { Taller sobre el proyecto } \\
\text { terapéutico singular. }\end{array}$ \\
\hline Caso 2 & $\begin{array}{l}\text { Víctima de violencia sexual en la } \\
\text { infancia y en la adolescencia. } \\
\text { Usuario de drogas: cocaína. } \\
\text { Transexual: hombre transexual. } \\
\text { Situación de salud diagnos- } \\
\text { ticada en prisión: múltiples } \\
\text { enfermedades, con énfasis en el } \\
\text { VIH, el HTLV-I y adicción severa. } \\
\text { Utiliza muletas para locomoción } \\
\text { y bolsa de urostomía. } \\
\text { Edad: } 25 \text { años. } \\
\text { Maternidad: hijo que se encuen- } \\
\text { tra en casa de acogida, resulta- } \\
\text { do de la violación por parte de } \\
\text { su padrastro. } \\
\text { Compañera: relación estable con } \\
\text { su compañera de celda. } \\
\text { Red de apoyo actual: abuela. } \\
\text { Delito: homicidio (víctima } \\
\text { padrastro). } \\
\text { Reincidente: estuvo en prisión } \\
\text { por tráfico de drogas. }\end{array}$ & $\begin{array}{l}\text { Se solicitó la prisión domiciliaria, } \\
\text { siendo concedida por la justicia. } \\
\text { Elaboración de un plan de } \\
\text { atención y acompañamiento en } \\
\text { salud, que cuenta con deriva- } \\
\text { ción a la atención especializada. } \\
\text { Articulación con el Programa } \\
\text { Salud de la Familia ejecutado en } \\
\text { el local del domicilio. } \\
\text { Sensibilización en lo referente a } \\
\text { la opción sexual, como acogida } \\
\text { y tratamiento por el nombre } \\
\text { social. }\end{array}$ & $\begin{array}{l}\text { Taller sobre género. } \\
\text { Taller sobre el proyecto } \\
\text { terapéutico singular. }\end{array}$ \\
\hline
\end{tabular}


Tabla 3. Resultados del soporte matricial (continuación)

\begin{tabular}{|c|c|c|c|}
\hline Dimensiones & $\begin{array}{r}\text { Soporte a } \\
\text { (apoyo y cuida }\end{array}$ & $\begin{array}{l}\text { asistencial } \\
\text { lado de la salud) }\end{array}$ & $\begin{array}{l}\text { Soporte técnico- } \\
\text { pedagógico } \\
\text { (apoyo a acciones } \\
\text { educativas) }\end{array}$ \\
\hline $\begin{array}{l}\text { Diagnóstico e } \\
\text { intervención }\end{array}$ & $\begin{array}{c}\text { Principales factores de } \\
\text { vulnerabilidad } \\
\text { antes y durante el } \\
\text { encarcelamiento }\end{array}$ & $\begin{array}{c}\text { Acciones conjuntas entre el EABp } \\
\text { y el equipo matriciador }\end{array}$ & $\begin{array}{l}\text { Educación continuada } \\
\text { en salud }\end{array}$ \\
\hline Caso 3 & $\begin{array}{l}\text { Abandono y negligencia familiar: } \\
\text { residió en la calle. } \\
\text { Usuaria de drogas: crack. } \\
\text { Situación de salud diagnosticada } \\
\text { en prisión: acompañamiento } \\
\text { prenatal en prisión. Nunca había } \\
\text { accedido a estos servicios fuera } \\
\text { de la cárcel. } \\
\text { Edad: } 26 \text { años. } \\
\text { Maternidad: se encuentra } \\
\text { embarazada (39 semanas) } \\
\text { y tiene otros } 3 \text { hijos. } \\
\text { Compañero: tiene orden de pri- } \\
\text { sión, pero ha huido de la justicia. } \\
\text { Red de apoyo actual: suegra. } \\
\text { Delito: tráfico de drogas. } \\
\text { Se encuentra próxima a la } \\
\text { excarcelación. } \\
\text { Reincidente: estuvo en prisión } \\
\text { por distintos delitos. }\end{array}$ & $\begin{array}{l}\text { El caso fue llevado al CAPS } \\
\text { AD de la región de la reclusa: } \\
\text { ha asumido el compromiso de } \\
\text { realizar el acompañamiento en } \\
\text { salud mental tras producirse su } \\
\text { excarcelación. } \\
\text { Articulación con el Programa } \\
\text { Salud de la Familia ejecutado en } \\
\text { el local donde reside la suegra. } \\
\end{array}$ & $\begin{array}{l}\text { Taller sobre género. } \\
\text { Taller sobre el proyecto } \\
\text { terapéutico singular. }\end{array}$ \\
\hline Caso 4 & $\begin{array}{l}\text { Víctima de violencia sexual en la } \\
\text { infancia y en la adolescencia. } \\
\text { Víctima de violencia doméstica } \\
\text { por parte del compañero. } \\
\text { Situación de salud diagnosticada } \\
\text { en prisión: problemas graves de } \\
\text { salud mental (ideación suicida y } \\
\text { posible diagnóstico de esquizo- } \\
\text { frenia). Se comprobó que, antes } \\
\text { de la entrada en prisión, era } \\
\text { acompañada por los servicios } \\
\text { comunitarios, como el RAPS, en } \\
\text { razón del diagnóstico de bipola- } \\
\text { ridad, intento de suicidio, víctima } \\
\text { de violencia, etc. } \\
\text { Edad: } 37 \text { años. } \\
\text { Maternidad: } 4 \text { hijas y } 1 \text { hijo. } \\
\text { Delito: violencia intrafamiliar por } \\
\text { omisión (víctimas: } 2 \text { hijas). } \\
\text { Compañero: autor de los deli- } \\
\text { tos que llevaron a la reclusa a } \\
\text { prisión. }\end{array}$ & $\begin{array}{l}\text { Se solicitó que la reclusa no fuera } \\
\text { trasladada al IPF. } \\
\text { Se solicitó su prisión domiciliaria. } \\
\text { Se llevó el caso al Tribunal de } \\
\text { Justicia: relectura del caso por } \\
\text { parte de la juez responsable y } \\
\text { acompañamiento por parte del } \\
\text { trabajador social. Articulación con } \\
\text { otros servicios psicosociales de } \\
\text { confianza de los juzgados para } \\
\text { reevaluación del caso. } \\
\text { Se ha diseñado una agenda con } \\
\text { el RAPS del local de residencia } \\
\text { de la reclusa, a ejecutar cuando } \\
\text { salga de prisión. }\end{array}$ & $\begin{array}{l}\text { Taller sobre género. } \\
\text { Taller sobre el proyecto } \\
\text { terapéutico singular. }\end{array}$ \\
\hline
\end{tabular}

Fuente: elaboración propia. 


\section{Discusión y conclusión}

Lejos de proponer cualquier generosidad represiva, los resultados de nuestro proyecto refuerzan la necesidad de diseñar políticas públicas específicas para las reclusas fundamentadas en la evidencia científica y a partir de la interseccionalidad entre género, salud pública y prisión. En primer lugar, ha de subrayarse que, en Río Grande del Sur, la población de mujeres reclusas ha experimentado un crecimiento del $160 \%$ entre 2004 y 2012 (se ha pasado de 800 a 2.074 mujeres). En comparación con la población nacional, los números regionales resultan alarmantes, ya que, en el mismo período, las mujeres en las prisiones de todo Brasil han experimentado un incremento del 93\% (es decir, han saltado de 18.790 a 35.039). A día de hoy, la región gaucha acoge el $6 \%$ de la población nacional de reclusas. El conocimiento de esta información ha sido posible porque, desde el año 2004, Brasil cuenta con un programa de recogida de datos del sistema penitenciario, el InfoPen. Sin embargo, su mantenimiento y actualización se realiza de forma dispar en cada región. Por tanto, la primera dificultad que se presenta para articular un trabajo con la población reclusa es la inconsistencia de los datos objetivos disponibles (Diniz-Gonçalves et al., 2010).

Pese a ello, este vertiginoso incremento no es una particularidad de Brasil o de nuestra región, por cuanto se verifica igualmente en otros países y con especial intensidad en el ámbito latinoamericano. El ICPS-International Centre for Prison Studies (Walmsley, 2015) constata que:

a) Desde el año 2000, el número de mujeres en situación de prisión ha aumentado cerca del $50 \%$ en el mundo.

b) Actualmente, Brasil es el tercer país latinoamericano con mayor número de reclusas, encabezando la lista Argentina y Bolivia.

Diferentemente de lo que se podría pensar, estos números no se explican a partir del aumento de las poblaciones y resultan más elevados que el encarcelamiento masculino, cuyo crecimiento ha sido de aproximadamente el $20 \%$ en el mismo período (Walmsley, 2015). Este fenómeno global se debe, en mayor medida, a cuestiones como el diseño de los modelos contemporáneos de justicia criminal, las políticas de enfrentamiento del tráfico de drogas y los costes del encarcelamiento comparados con las políticas de prevención del delito (Carlen, 2002; Downes y Rock, 2011; Medina-Ariza, 2011; Wacquant, 2001).

Es responsabilidad ineludible de los estados, pues, realizar reformas que incluyan desde la profunda revisión de las estrategias de enfrentamiento del tráfico de drogas y la inclusión de alternativas al encarcelamiento hasta el diseño de programas que puedan proporcionar a las mujeres un proyecto de vida sin delitos en el momento de su excarcelación (WOLA, 2016; AIDEFEUROSociALII, 2015). Hablando sobre la salud de las reclusas, ha de puntualizarse que la misma presenta notables carencias en relación con los demás grupos de población y supone un reto para los sistemas sanitarios de cada país (Bergh et al., 2011). En definitiva, se trata de poner de manifiesto cómo 
la cárcel opera como un agente discriminador de género (Mapelli-Caffarena et al., 2012).

Nos arriesgamos a afirmar que nuestro estudio comprueba que los más vulnerables — al menos en la región sur de Brasil- son los que llevan el peso de políticas criminales altamente represivas combinadas con la ausencia de políticas sociales eficaces de inclusión. De una parte, el análisis de la situación psicosocial de las mujeres privadas de libertad en la cárcel Madre Pelettier ha revelado las múltiples victimizaciones sufridas antes de su ingreso en prisión: pobreza extrema, abandono familiar, ausencia de estudios, violaciones en la infancia y en la adolescencia, violencia por parte del compañero íntimo, portadoras de VIH y enfermedades mentales graves, entre otras. La comisión del delito aparece directamente vinculada a esta auténtica ruta de victimización, ampliamente reconocida en el ámbito internacional (Chesney-Lind y Rodríguez, 2003; Daly, 1992, 1994; Yagüe-Olmos, 2002; Mapelli-Caffarena et al., 2013). De otra parte, se ha demostrado que las condiciones de vulnerabilidad de las reclusas se acentúan con el ingreso en prisión: ocupan espacios físicos improvisados y apenas reciben inversión financiera, viven situaciones de aislamiento, homogeneización y disciplina vinculada a la sobremedicalización y no cuentan con programas de deporte ni de inserción laboral. Sobre ese último punto, los programas laborales, cuando existen, reproducen los roles de dependencia y domesticación, como los cursos de maquillaje y las tareas de limpieza. La situación penitenciaria descrita se asemeja a la denunciada por la criminología de corte feminista (Almeda-Samaranch, 2002; AlmedaSamaranch y Bodelón, 2007; Añaños, 2010; Carlen y Worrall, 2004; Proyecto MIP, 2005), incluyéndose la que revela que no es infrecuente que la primera toma de contacto de una mujer con un servicio de salud se produzca en el momento en que ingresa en prisión (Del Val-Cid, 2012). Lo que sí parece ser diferente en nuestra región es la tardanza por parte de los órganos oficiales en el reconocimiento de este escenario y la puesta en marcha de estrategias para su superación (¡La PNAMP es del año 2014!).

Visibilizar nuestra realidad es asumir el compromiso de impedir su neutralización y tolerancia. En esta línea, consideramos de especial interés la posibilidad de implantar una política pública de salud específica para la población privada de libertad incentivada por el sistema de salud pública en vigor para la población fuera de prisiones: el SUS. Articular el SUS intramuros requiere que la habilitación de EABp se despliegue en paralelo a la profundización del conocimiento sobre las especificidades de género en prisión y a la articulación con los demás servicios ofrecidos en el ámbito comunitario, ambas hipótesis de partida de la presente investigación.

El enfoque de género en prisión se fundamenta en el modelo de atención al género en prisión, que propone la elección de un local más adecuado para el cumplimento de la pena, de funcionariado preparado y de desarrollo de programas (Bloom y Covington, 2000). En otras palabras, insta a que las acciones y las actividades dentro de prisiones tomen en cuenta factores exógenos (vinculados a la privación de libertad y a la administración penitenciaria) 
y endógenos (vinculados a la propia condición de mujer), como, por ejemplo: infraestructuras masculinizadas, una necesaria coordinación de la salud mental con políticas y programas de prevención de suicidio, itinerario hacia el sistema de justicia penal marcado por la violencia sufrida antes del ingreso en prisión, desigualdades sociales y adicción a substancias tóxicas (COMJIB, 2013).

Consiguientemente, el trabajo en salud intramuros debe incorporar las especificidades y las necesidades reales de las mujeres, así como las desigualdades de las que parten (Proyecto MIP, 2005). La salud asume una dimensión colectiva, cuyo estatus de derecho humano pasa por la articulación con una red de servicios, como los comunitarios. Desde esta perspectiva, la prisión se presenta como un entorno que apoya la salud, como estrategia clara para su promoción y prevención (OMS, 1986). Idea esta recogida en las Reglas de Bangkok (apartado 6. Servicios de Atención de Salud), que prevén, entre otras cuestiones, que los servicios de atención a la salud en prisiones deben ser equivalentes a los que se prestan en la comunidad y que la prevención y el tratamiento deben estar contextualizados en las especificidades de género.

El análisis conjunto de los grupos focales y del soporte matricial realizado en nuestro estudio ha revelado que, tras la habilitación del EABp, la labor de atención, cuidado y promoción de salud desarrollada intramuros más bien se ha debido al interés y al compromiso de cada profesional que al conocimiento de susodichas cuestiones y a su incorporación a las prácticas laborales (la primera hipótesis de partida del proyecto se confirma parcialmente, mientras que la segunda se confirma integralmente). La mayor interacción entre la academia y los profesionales constituye una pieza clave para la transformación de esta problemática realidad.

Nos arriesgamos a afirmar que la pluralidad metodológica utilizada en el trabajo de campo ha favorecido un cambio de perspectiva, concediéndose prioridad a la salud en detrimento de la función de custodia regimental. Destacamos, por ejemplo, el hecho de que el EABp se apoye en su labor en el significado de salud propuesto por la Organización Mundial de la Salud (OMS, 1946): «un estado de completo bienestar físico, mental y social, y no solamente la ausencia de afecciones o enfermedades». Como corolario, el trabajo en salud mental asume como base no solo la ausencia de trastornos mentales, sino también una serie de estrategias destinadas a lograr resultados positivos, como el desarrollo de recursos y capacidades individuales y la mejora de la situación socioeconómica. Si bien resulta evidente que el EABp es consciente de las dificultades de ejecutar este modelo de salud intramuros, subrayamos su entendimiento acerca de la transitoriedad de la situación de prisión y el darse cuenta de la victimización de muchas reclusas en su trayectoria vital. La atención al género deja de ser elemento extraño al medio carcelario (Mapelli-Caffarena et al., 2012).

De hecho, los profesionales de la salud reconocen que pocas reclusas podrían ser consideradas una amenaza social, toda vez que sus delitos están vinculados en mayor medida al transporte o a la distribución de drogas a pequeña escala, generalmente practicados como una manera de afrontar la pobreza o incluso por la coacción de la pareja u otro familiar. Además, refuerzan la idea 
de que la prisión suele empeorar la situación de vida de las mujeres, puesto que perpetúa el círculo vicioso de pobreza, uso de drogas y múltiples problemas que afectan a su salud. Justamente en base a este diagnóstico, los profesionales reconocen como un punto de mejora de su trabajo la fragmentación de los cuidados y las redes en el ámbito comunitario. Lo interesante de este análisis es que acompaña a los escasos estudios ya realizados en el gigante americano (Diniz-Gonçalves et al., 2010; Falcade-Pereira y Asinelli-Luz, 2015; Queiroz, 2015; Relatório sobre mulheres encarceradas no Brasil, 2007; Grupo de Trabalho Interministerial, 2014) y coincide con los provenientes de entornos considerados más desarrollados que denuncian la dificultad de estructurar y ofrecer intramuros, y de forma articulada, los mismos servicios extramuros (téngase como ejemplo el caso de España en GSMP, 2011).

Como cierre de este trabajo, nos oponemos a la invisibilidad de las condiciones de vida de las reclusas antes, durante y después del cumplimiento de la pena y a una estrategia de encarcelamiento que en poco o nada contribuye a mejorar la seguridad pública. Al mismo tiempo, reforzamos la importancia de cualificar las acciones y mejorar los servicios de salud implementados en prisión, así como de apostar por la creación de una línea de cuidado de atención integral a la salud de las mujeres privadas de libertad con recorte de género que sirva de fundamento para el futuro diseño de programas en prisiones (COMJIB, 2013; Del Pozo-Serrano y Añaños-Bedriñana, 2013; Sordi-Stock, 2016). El propósito último es fomentar la cultura de los derechos humanos por medio del acceso - sin distinción - a un conjunto de servicios y programas que favorezcan la integración social de las mujeres.

\section{Referencias bibliográficas}

AIDEF-EUROSociAL II (2015). Manual regional: Las Reglas de Bangkok en clave de defensa pública [en línea]. <http://eurosocial-ii.eu/es/showbiblioteca/5356> [Consulta: 20 septiembre 2016].

Almeda-Samaranch, Elisabeth (2002). Corregir y castigar: El ayer y hoy de las cárceles de mujeres. Barcelona: Bellaterra.

Almeda-Samaranch, Elisabeth y Bodelón, Encarna (ed.) (2007). Mujeres y castigo: Un enfoque socio-jurídico y de género. Madrid: Dykinson. Oñati: Derecho y Sociedad.

Anais do IV Seminário Nacional de Estudos Prisionais - III Fórum sobre vitimização de mulheres no sistema de justiça criminal. Mulheres e jovens no cárcere. Perspectiva diante da vitimização e da punição de mulheres no Brasil contemporâneo. Marília: FUNDEPE, UNESP, 2014.

AÑaños, Fanny (coord.) (2010). Las mujeres en las prisiones: La educación social en contextos de riesgo y conflicto. Barcelona: Gedisa.

Bardin, Laurence (1977). Análise de Conteúdo. Lisboa: Ediçōes 70.

Bergh, Brenda J. van den; Gatherer, Alex; Fraser, Andrew y Moller, Lars (2011). «Privación de libertad y salud de la mujer: Inquietudes sobre la sensibilidad de género, los derechos humanos y la sanidad pública». Boletín de la Organización Mundial de la Salud [en línea], 89 (9), 621-700. $<$ http://dx.doi.org/10.2471/blt.10.082842>. 
Bloom, Barbara E. y Covington, Stephanie S. (2000). «Gendered justice: Programming for women in correctional settings». 52nd Annual Meeting of the American Society of Criminology [en línea]. EE. UU., San Francisco. <http://www.centerforgenderandjustice.org/assets/files/11.pdf> [Consulta: 20 septiembre 2016].

Campos, Carmen Hein (1999). Criminologia e Feminismo. Porto Alegre: Sulina.

Campos, Gastão Wagner de Sousa y DomitTi, Ana Carla (2007). "Apoio matricial e equipe de referencia: Uma metodologia para gestão do trabalho interdisciplinar em saúde». Cadernos de Saúde Pública [en línea], 23 (2), 399-407. <http://dx.doi.org/10.1590/S0102-311X2007000200016>.

Canazaro, Daniela y Argimon, Irani Iracema de Lima (2010). «Características, sintomas depressivos e fatores associados em mulheres encarceradas no Estado do Rio Grande do Sul, Brasil». Cadernos de Saúde Pública [en línea], 26 (7), 1323-1333. <http://dx.doi.org/10.1590/S0102-311X2010000700011>.

Carlen, Pat (ed.) (2002). Women and Punishment: The Struggle for Justice. Cullompton: Willan.

Carlen, Pat y Worrall, Anne (2004). Analysing Women's Imprisonment. Cullompton: Willan.

Carvalho, Márcia Lazaro de; Valente, Joaquim Gonçalves; Assis, Simone Gonçalves de y Vasconcelos, Ana Glória Godoi (2006). «Perfil dos internos no sistema prisional do Rio de Janeiro: Especificidades de gênero no processo de exclusão social». Ciências e Saúde Coletiva [en línea], 11 (2), 461-471. <http://dx.doi.org/10.1590/S1413-81232006000200023>.

Chesney-Lind, Meda y Rodriguez, Noeli (2003). "Women under Lock and Key: A View from the Inside». En: Chesney-Lind, Meda y Pasko, Lisa (Org). Girls, Women and Crime [en línea]. California: Selected Readings. <http://dx.doi.org/10.4135/9781483387574>.

Chies, Luiz Antônio Bogo (2008). "Gênero, Criminalização, Punição e "Sistema de Justiça Criminal": Um olhar sobre as sobrecargas punitivas e as dominações do masculino». Revista de Estudos Criminais, 8, 81-105.

Colares, Leni Beatriz Correia y Chies, Luiz Antônio Bogo (2010). «Mulheres nas so(m)bras: Invisibilidade, reciclagem e dominação viril em presídios masculinamente mistos». Estudos Feministas, 18 (2), 407-423.

COMJIB (2013). Programa Modelo de Género en contexto de privación de libertad para Iberoamérica [en línea]. <http://www.comjib.org/publicaciones/programa-regionalde-genero> [Consulta: 20 septiembre 2016].

Costa, Diogo Faria Corrêa y Paulon, Simone Mainieri (2012). «Participação Social e protagonismo em saúde mental: A insurgência de um coletivo». Revista Saúde em Debate [en línea], 36 (95), 572-582. <http://dx.doi.org/10.1590/S0103-11042012000400009>.

DALY, Kathleen (1992). «Women's pathways to felony court: Feminist theories of lawbreaking and problems of representation». Review of Law and Women Studies, 2 (1).

- (1994). Gender, crime and punishment. New Haven: Yale University Press.

- (1997). «Different Ways of Conceptualizing Sex/Gender in Feminist Theory and their Implications for Criminology». Theoretical Criminology [en línea], 1 (1). <http://dx.doi.org/10.1177/1362480697001001003>.

Diniz-Gonçalves, Betânea; Simốes-Coelho, Carolina Marra y Vilas-Boas, Cristina Campolina (2010). Mulheres em Situação de privação de liberdade: Vida na prisão e perspectivas futuras [en línea]. Relatório Final de Pesquisa. Belo Horizonte: Pontifícia Universidade Católica de Minas Gerais. <http://www.saogabriel.pucminas. 
br/psicologia/wp-content/uploads/2012/11/Mulheres-em-situação-de-privação-de-liberdade-a-vida-na-prisão-e-perspectivas-futuras-relatório-final-CRP.pdf> [Consulta: 20 septiembre 2016].

Dotta-Panichi, Renata Maria (2014). The Right to Health: Women in Prison and Mental Healt. Porto Alegre: Universidade de Ciências da Saúde de Porto Alegre. Tesis de doctorado.

Dotta-Panichi, Renata; Sordi-Stock, Bárbara; Kunn, Giovanni F.; Martins, Lairton Bueno; Shultz, Águida L. y Fuzzinatto, Aline M. (2014). «Apoio Matricial em saúde mental a equipes de atenção básica inseridas no sistema prisional: Novos olhares». En: Anais - IV Seminário Nacional de Estudos Prisionais - III Fórum sobre vitimização de mulheres no sistema de justiça criminal. Mulheres e jovens no cárcere. Perspectiva diante da vitimização e da punição de mulheres no Brasil contemporâneo. Marília: FUNDEPE, UNESP.

Downes, David y Rock, Paul (2011). Sociología de la desviación: Una guia sobre las teorías del delito. Barcelona: Gedisa.

Espinoza, Olga (2004). A mulher encarcerada em face do poder punitivo. São Paulo: IBCCrim.

Falcade-Pereira, Ires Aparecida y Asinelli-Luz, Araci (2015). Ética do cuidado $x$ Ética da justiça: O olhar feminino de mulheres privadas de liberdade. Curitiba: Novas Edições Acadêmicas.

Ferreira-Júnior, Sérgio; Oliveira, Helenice Bosco de y Marin-Léon, Letícia (2013). «Knowledge, attitudes and practices on tuberculosis in prisons and public health services». Revista Brasileira de Epidemiologia [en línea], 16 (1), 100-113. <http://dx.doi.org/10.1590/S1415-790X2013000100010>.

Franco, Camilla Maia y Franco, Túlio Batista (2011). Linha do Cuidado Integral: Uma proposta de organização da rede de saúde [en línea]. <http://www.saude.rs. gov.br/upload/1337000728_Linha\%20cuidado\%20integral\%20conceito $\% 20$ como\%20fazer.pdf> [Consulta: 20 septiembre 2016].

Franco, Túlio Batista y Magalhães, Helvécio Miranda (2003). "A Integralidade e as Linhas de Cuidado». En: Merhy, Emerson Elias et al. (org.). O Trabalho em Saúde: Olhando e Experienciando o SUS no Cotidiano. São Paulo: Hucitec.

Gaskell, George (2004). «Entrevistas Individuais e Grupais». En: Bauer, Martin W. de y Gaskell, George (org.). Pesquisa Qualitativa com Texto, Imagem e Som: Um manual prático. Petrópolis, RJ: Vozes.

Grupo de Trabalho Interministerial (2014). Política Nacional de Atenção às Mulheres em Situação de Privação de Liberdade e Egressas do Sistema Prisional: Documento Basilar para a Elaboração da Portaria Interministerial MJ/SPM no 210/2014 [en línea]. <http://www.justica.gov.br/seus-direitos/politica-penal/politicas-2/ mulheres-1/anexos-projeto-mulheres/doc-basilar-politica-nacional-versao-final. pdf> [Consulta: 20 septiembre 2016].

GSMP (2011). Guía Atención Primaria de la Salud Mental en Prisión. Bilbao: OM Editorial.

Guedes, Marcela Ataide (2006). «Intervenções psicossociais no sistema carcerário feminino». Psicologia Ciência e Profissão, 26 (4), 558-569.

InfoPen, Sistema Nacional de Informaciones Penitenciarias [en línea]. <http://www. infopen.gov.br/> [Consulta: 20 septiembre 2016].

KERR, Lígia (coord.) (2011 - actual). Inquérito nacional sobre saúde e violência na população penitenciária feminina e em servidoras prisionais. Universidade Federal do Ceará. Faculdade de Medicina. Departamento de Saúde Comunitária. 
KInd, Luciana (2004). «Notas para o trabalho com a técnica de grupos focais». Psicologia em Revista, 10 (15), 124-36.

Lemgruber, Julita (1999). Cemitério dos vivos: Análise sociológica de uma prisão de mulheres. 2. ${ }^{\mathrm{a}}$ ed. Río de Janeiro: Forense.

Mapelli-Caffarena, Borja; Herrera-Moreno, Myriam y Sordi-Stock, Bárbara (2013). «La exclusión de las excluidas. ¿Atiende el sistema penitenciario a las necesidades de género?: Una visión andaluza». Estudios Penales y Criminológicos, 33, 59-95.

Mapelli-Caffarena, Borja; Sordi-Stock, Bárbara; Aguado-Correa, Teresa; Herrera-Moreno, Myriam y Gutiérrez, Francisco (2012). Mujeres en las cárceles de Andalucía. Madrid: Dykinson.

Medina-Ariza, Juanjo (2011). Políticas y estrategias de prevención del delito y seguridad ciudadana. Montevideo / Buenos Aires: B de $f$.

OMS (1946). Constitución de la Organización Mundial de la Salud [en línea]. Nueva York. <http://www.who.int/about/mission/es/> [Consulta: 20 septiembre 2016].

- (1986). Carta de Ottawa para el Fomento de la Salud: Primera Conferencia Internacional sobre Fomento de la Salud, Ottawa [en línea]. Canadá. <http://www.who. int/healthpromotion/conferences/previous/ottawa/en/> [Consulta: 20 septiembre 2016].

PessôA, Luisa Regina (org.) (2011). Manual do Gerente: Desafios da média gerência na saúde [en línea]. Río de Janeiro: ENSP. <http://www5.ensp.fiocruz.br/biblioteca/ dados/txt_379517240.pdf> [Consulta: 20 septiembre 2016].

Pozo-Serrano, Francisco José del y Añaños-Bedriñana, Fanny T. (2013). «La Educación Social Penitenciaria: ¿De dónde venimos y hacia dónde vamos?». Revista Complutense de Educación, 24 (1), 47-68.

Proyecto MIP (2005). Mujeres, Integración y Prisión: Análisis de los procesos de integración socio-laboral de las mujeres presas en Europa [en línea]. <http://surt.org/ publicacions/estudis/> [Consulta: 20 septiembre 2016].

Queiroz, Nana (2015). Presos que menstruam: A brutal vida das mulheres - tratadas como homens - nas prisões brasileiras. São Paulo: Record.

Relatório sobre mulheres encarceradas no Brasil (2007) [en línea]. <http://www.asbrad. com.br/conte\%C3\%BAdo/relat\%C3\%B3rio_oea.pdf> [Consulta: 20 septiembre 2016].

SES/RS, Secretaria de Saúde do Estado do Rio Grande do Sul [en línea]. <http://www. saude.rs.gov.br/> [Consulta: 20 septiembre 2016].

Sordi-STOCK, Bárbara (2016). «Programas para agresores de violencia de género en prisión: ¿Avanzamos o caminamos en círculos?». Estudios Penales y Criminológicos, 36, 79-129.

UNAIDS-OMS (2007). HIVIAIDS em ambientes prisionais: Prevenção, atenção, tratamento e apoio. Marco referencial para uma resposta nacional eficaz [en línea]. Nueva York: Organização Mundial da Saúde e Programa Conjunto das Nações Unidas sobre HIV/AIDS. <https://www.unodc.org/documents/hiv-aids/07-85461_Prison_Framework_Portugese.pdf> [Consulta: 20 septiembre 2016].

VAL-Cid, Consuelo del (2012). "V. Encierro y Derecho a la Salud». En: VAL-Cid, Consuelo del y Viedma-Rojas, Antonio (eds.). Condenadas a la desigualdad: Sistema de indicadores de discriminación penitenciaria. Barcelona: Icaria, 109-141.

Val-Cid, Consuelo del y Viedma-Rojas, Antonio (eds.) (2012). Condenadas a la desigualdad: Sistema de indicadores de discriminación penitenciaria. Barcelona: Icaria.

WaCQUANT, Loïc (2001). As prisões da Miséria. Río de Janeiro: Jorge Zahar. 
Walmsley, Roy (2015). World Female Imprisonment List. 3. a ed. Londres: ICPS-International Centre for Prison Studies.

WOLA (2016). Women, Drug Policies, and Incarceration: A Guide for Policy Reform in Latin America and the Caribbean [en línea]. <http://www.wola.org/sites/default/ files/WOLA\%20WOMEN\%20FINAL\%20ver\%2025\%2002\%201016.pdf> [Consulta: 20 septiembre 2016].

Wolff, Maria Palma (2010). «Mulheres e tráfico de drogas: Uma perspectiva de gênero». Revista Brasileira de Ciências Criminais, 18 (87), 375-395.

Wolff, Maria Palma et al. (org.) (2007). Mulheres e Prisão: A experiência do Observatório de Direitos Humanos da Penitenciária Feminina Madre Pelletier. Porto Alegre: Dom Quixote.

Yagüe-Olmos, C. (2002). «Mujer, delito y prisión: Un enfoque diferencial sobre la delincuencia femenina». Revista de Estudios Penitenciarios, 246.

$1^{\circ}$ Encontro Nacional do Projeto Mulheres (2012) [en línea]. DEPEN-MJ. <http://www. justica.gov.br/seus-direitos/politica-penal/politicas-2/mulheres-1> [Consulta: 20 septiembre 2016].

$2^{o}$ Encontro Nacional do Projeto Mulheres (2013) [en línea]. DEPEN-MJ. <http:// www.justica.gov.br/seus-direitos/politica-penal/politicas-2/mulheres-1> [Consulta: 20 septiembre 2016].

$3^{\circ}$ Encontro Nacional do Projeto Mulheres (2014) [en línea]. DEPEN-MJ. <http://www. justica.gov.br/seus-direitos/politica-penal/politicas-2/mulheres-1> [Consulta: 20 septiembre 2016].

\section{Normativa}

CF (1988). Constituição da República Federativa do Brasil [en línea]. <http://www. planalto.gov.br/ccivil_03/constituicao/constituicaocompilado.htm> [Consulta: 20 septiembre 2016].

Comissão Especial, vinculada à Diretoria de Politicas Penitenciárias do Departamento Penitenciário Nacional, para elaborar propostas de açôes para o Projeto Estratégico do Ministério da Justiça: Efetivação dos Direitos das Mulheres do Sistema Penal [en línea]. Portaria, 154 (13 de abril de 2012). <http://www.justica.gov.br/seus-direitos/politica-penal/politicas-2/mulheres-1/anexos-projeto-mulheres> [Consulta: 20 septiembre 2016].

Ley 7.210, 11 de junio de 1984. Lei de Execuçôes Penais [en línea]. <http://www.planalto.gov.br/ccivil_03/leis/L7210.htm>[Consulta: 20 septiembre 2016].

Ley 8.080, 19 de septiembre de 1990. Condições para a promoção, proteção e recuperação da saúde, a organização e o funcionamento dos serviços correspondentes e dá outras providências [en línea]. <http://www.planalto.gov.br/ccivil_03/leis/18080.htm> [Consulta: 20 septiembre 2016].

Ley 8.142, 28 de diciembre de 1990. Participação da comunidade na gestão do Sistema Único de Saúde (SUS) e sobre as transferências intergovernamentais de recursos financeiros na área da saúde e dá outras providências [en línea] <http://www.planalto.gov.br/ccivil_03/leis/18142.htm> [Consulta: 20 septiembre 2016].

PNAISP (2014). Política Nacional de Atenção Integral à Saúde das Pessoas Privadas de Liberdade no Sistema Prisional (PNAISP) no âmbito do Sistema Único de Saúde (SUS) [en línea]. Portaria Interministerial MS/ML, 1 (2 de enero de 2014). <http://portalsaude.saude.gov.br/index.php/o-ministerio/principal/secretarias/ sas/saude-no-sistema-prisional> [Consulta: 20 septiembre 2016]. 
- (2014a). Aprova as normas de operacionalização e financiamento da Política Nacional de Atenção Integral à Saúde no Sistema Prisional [en línea]. Portaria GM/MS, 482 (1 de abril de 2014). <http://portalsaude.saude.gov.br/index.php/o-ministerio/ principal/secretarias/sas/saude-no-sistema-prisional> [Consulta: 20 septiembre 2016].

PNAMP (2014). Política Nacional de Atenção às Mulheres em Situação de Privação de Liberdade e Egressas do Sistema [en línea]. Portaria Interministerial, 210 (16 de enero de 2014). <http://portalsaude.saude.gov.br/index.php/o-ministerio/princi$\mathrm{pal} / \mathrm{secretarias} / \mathrm{sas} /$ saude-no-sistema-prisional> [Consulta: 20 septiembre 2016].

PNSSP (2003). Plano Nacional de Saúde no Sistema Penitenciário [en línea]. Portaria Interministerial MS/MJ, 1.777 (9 de septiembre de 2003). <http://portalsaude. saude.gov.br/index.php/o-ministerio/principal/secretarias/sas/saude-no-sistemaprisional> [Consulta: 20 septiembre 2016].

Reglas de Bangkok (2011). Reglas de las Naciones Unidas para el tratamiento de las reclusas y medidas no privativas de la libertad para las mujeres delincuentes [en línea]. $<$ https://www.unodc.org/ropan/es/PrisonReform/Reglas_de_Bangkok/presentacion.html> [Consulta: 20 septiembre 2016].

Resolución CIB/RS n. ${ }^{\circ}$ 257/2011. Aprova a alteração do Incentivo Estadual para habilitação de Equipes Municipais de Saúde Prisional em unidades penitenciárias com mais de 100 pessoas presas [en línea]. <http://www.saude.rs.gov.br/> [Consulta: 20 septiembre 2016]. 